\title{
Stomagen positively regulates stomatal density in Arabidopsis.
}

\section{$\operatorname{AUTHOR}(\mathrm{S}):$}

Sugano, Shigeo S; Shimada, Tomoo; Imai, Yu; Okawa, Katsuya; Tamai, Atsushi; Mori, Masashi; Hara-Nishimura, Ikuko

\section{CITATION:}

Sugano, Shigeo S ... [et al]. Stomagen positively regulates stomatal density in Arabidopsis.. Nature 2009, 463: 241-244

\section{ISSUE DATE:}

2009-12-09

URL:

http://hdl.handle.net/2433/91250

\section{RIGHT:}

c 2009 Nature Publishing Group All Rights Reserved. 許諾条件により本 文は2010-06-10に公開.; This is not the published version. Please cite only the published version.; この論文は出版社版でありません。引用の 際には出版社版をご確認ご利用ください。 


\title{
Stomagen positively regulates stomatal density in Arabidopsis
}

\author{
Shigeo S. Sugano ${ }^{1}$, Tomoo Shimada ${ }^{1}$, Yu Imai ${ }^{1}$, Katsuya Okawa ${ }^{2}$, Atsushi Tamai ${ }^{3}$, Masashi \\ Mori $^{3}$ \& Ikuko Hara-Nishimura ${ }^{1}$ \\ ${ }^{1}$ Graduate School of Science, Kyoto University, Sakyo-ku, Kyoto 606-8502, Japan. ${ }^{2}$ Innovative Drug Research \\ Laboratories, Kyowa Hakko Kirin Co., Ltd., Taksasaki 370-1295, Japan. ${ }^{3}$ Research Institute for Bioresources and \\ Biotechnology, Ishikawa Prefectural University, Nonoichi-machi, Ishikawa 921-8836, Japan.
}

*These authors contributed equally to this work.

Stomata in the epidermal tissues of leaves are valves through which passes $\mathrm{CO}_{2}$, and as such they influence the global carbon cycle ${ }^{1}$. The two-dimensional pattern and density of stomata in the leaf epidermis are genetically and environmentally regulated to optimize gas exchange $^{2}$. Two putative intercellular signalling factors, EPF1 and EPF2, function as negative regulators of stomatal development in Arabidopsis, possibly by interacting with the receptor-like protein $\mathrm{TMM}^{3-6}$. One or more positive intercellular signalling factors are assumed to be involved in stomatal development, but their identities are unknown ${ }^{7}$. Here we show that a novel secretory peptide, which we designate as stomagen, is a positive intercellular signalling factor that is conserved among vascular plants. Stomagen is a 45-amino-acid, cysteine-rich peptide that is generated from a 102-amino-acid precursor protein designated as STOMAGEN. Both an in planta analysis and a semi-in-vitro analysis with recombinant and chemically synthesized stomagen peptides showed that stomagen has stomata-inducing activity in a dose-dependent manner. A genetic analysis showed that TMM is epistatic to STOMAGEN (At4g12970), suggesting that stomatal development is finely regulated by competitive binding of positive and negative regulators to the same receptor. Notably, STOMAGEN is expressed in inner tissues (the mesophyll) of immature leaves but not in the epidermal tissues where stomata develop. This study provides evidence of a mesophyll-derived positive regulator of stomatal density. Our findings provide a conceptual advancement in understanding stomatal development: inner photosynthetic tissues optimize their function by regulating stomatal density in the epidermis for efficient uptake of $\mathrm{CO}_{2}$.

Stomatal development in leaves is negatively regulated by putative cell-surface receptors TOO MANY MOUTHS (TMM) and ERECTA family receptor-like kinases (ER, ERL1 and ERL2) ${ }^{3,8}$. Two possible ligands of these receptors, EPIDERMAL PATTERNING FACTOR (EPF) 1 and EPF2, act as negative signalling factors at distinct steps during stomatal development ${ }^{4-6}$. Another negative regulator, STOMATAL DENSITY AND DISTRIBUTION 1 (SDD1), which is a subtilisin-type proteinase, is reported to be dependent on $\mathrm{TMM}^{9}$. Although positive signalling factors are thought to exist ${ }^{6,7,10}$, no signalling factors are known to positively regulate stomatal development in leaves.

To identify novel positive signalling factors, we first selected genes that are co-expressed with a set of $T M M, S D D 1$ and EPF1 by using in silico screening with a transcriptome database of Arabidopsis thaliana, ATTED-II ${ }^{11}$ (Supplementary Table 1). This analysis identified a gene (At4g12970) that encodes EPFL9, a member of the EPF family, whose function was unknown ${ }^{6}$. Interestingly, overexpression of the At4g12970 gene resulted in an increase of stomatal density of various organs that naturally produce stomata (leaves, cotyledons, stems, fruits and anthers) in each of 13 overexpression lines that we established ( $n=7$ for each T2 line, Fig. 1a and Supplementary Fig. 1). This phenotype contrasts with a decreased stomatal density phenotype in transgenic plants overexpressing $E P F 1$ or $E P F 2^{4-6}$. We named the At4g12970 gene STOMAGEN after its stoma-generating activity.

Stomata in most dicotyledonous plants are separated by at least one non-stomatal cell ${ }^{12}$, which is thought to improve the efficiency of gas exchange ${ }^{2}$. The overexpression lines of STOMAGEN (STOMAGEN-OX) exhibited many clustered stomata in mature leaves (Fig. 1a) and formed satellite meristemoids (stomatal precursor cells) adjacent to guard cells or their precursors in immature cotyledons (Supplementary Fig. 2), indicating that the orientation of cell division in the stomatal lineage is defective in these lines. The abnormal clustering is probably due to the $35 \mathrm{~S}$ promoter-driven expression of STOMAGEN in the epidermis (see Fig. 2c, d).

We next examined the loss-of-function phenotype by gene silencing using an artificial microRNA that targeted the $3^{\prime}$ side of the coding region of STOMAGEN (Supplementary Fig. 3a). Fourteen independent T2 lines in which STOMAGEN was silenced by RNA interference (STOMAGEN-RNAi lines) had reduced stomatal densities in various organs (Fig. 1a and Supplementary Fig. 1). Other STOMAGEN-silenced lines made with another artificial microRNA (12 independent T2 lines) and 
double-stranded RNA (dsRNA; 4 independent T2 lines) exhibited the same phenotype (Supplementary Fig. 3), indicating that STOMAGEN is required for proper stomatal development. A quantitative analysis revealed a positive correlation between the expression level of STOMAGEN messenger RNA and either stomatal density or the stomatal index (defined as the ratio of stomata to stomata plus other epidermal cells) (Fig. 1b, c). Both the gain-of-function and loss-of-function phenotypes indicate that STOMAGEN is a positive regulator of stomatal development.

STOMAGEN was predominantly expressed in immature organs including leaves, stems and flower buds (Fig. 2a). $\beta$-Glucuronidase (GUS) activity in pSTOMAGEN::GUS lines was observed in immature cotyledons and developing leaves, but not in fully expanded cotyledons or leaves (Fig. 2b). These expression patterns are consistent with the fact that stomatal development starts in immature organs ${ }^{2}$. Notably, GUS activity was detected in the mesophyll tissues but not in the epidermal tissues where stomata develop (Fig. 2c). In situ RNA hybridization gave the same result (Fig. 2d). These results indicate that STOMAGEN is produced in mesophyll cells and that inter-tissue signalling regulates stomatal development in the epidermis. This provides a counterexample to previous reports that most regulatory genes for stomatal development are expressed in epidermal tissues $^{10,13,14}$. To determine whether STOMAGEN itself migrates from the mesophyll to the epidermis, we generated transgenic lines (12 independent T2 lines) that expressed a STOMAGEN-Venus fusion protein, which exhibited the same phenotype as STOMAGEN-OX (see Fig. 3d). Venus fluorescence was observed outside the plasmolysed cells (Fig. 2e and Supplementary Fig. 4), indicating that STOMAGEN is secreted from the cells to the apoplast. In previous studies, mesophyll-epidermis interactions have been limited to coordinating the airspace and stomata $^{12,15}$. The discovery of STOMAGEN will provide a valuable insight into mesophyll-epidermis interaction for stomatal density.

The STOMAGEN gene encodes a small protein of 102 amino acids with a putative signal peptide at its amino terminus (Fig. 3a). STOMAGEN-Venus, which was immunoprecipitated from the transgenic leaves with anti-GFP antibody, gave a single band on an immunoblot with anti-stomagen antibody (Fig. 3b). Edman degradation of the immunoprecipitate gave an N-terminal sequence of IGSTAPTXTY (where X indicates undetermined; Supplementary Fig. 5), which is identical to the sequence starting from Ile 58 of STOMAGEN. The N-terminal sequence is consistent with the N-terminal sequences obtained by matrix-assisted laser desorption/ionization time-of-flight mass spectrometry (MALDI-TOF/MS) analyses of lysyl endopeptidase and trypsin digests of the
IGSTAPTCTYNECRGCRYK and IGSTAPTCTYNECR, respectively (Fig. 3c). These results indicate that STOMAGEN is processed in vivo to produce the 45-amino-acid peptide that contains six cysteine residues. We designated the cysteine-rich peptide as stomagen. Expression of stomagen with a signal peptide at the $\mathrm{N}$ terminus, which lacked the propeptide domain, increased the stomatal density in the transgenic plants (10 independent T2 lines; Fig. $3 \mathrm{~d}$ ), indicating that the 45 -amino-acid peptide is sufficient to induce stomatal formation. Genes for stomagen-like peptides were found in various plant species (Supplementary Fig. 6). Interestingly, a similar peptide was found in Selaginella moellendorffii, a primitive vascular plant. Together, these results indicate that stomagen is widely distributed in vascular plants.

To obtain pure stomagen, tobacco-cultured BY-2 cells were transformed with the STOMAGEN gene. The culture medium was found to be immunopositive for stomagen and was fractionated with reverse-phase high-performance liquid chromatography (HPLC; Supplementary Fig. 7a, b). Several fractions were found to contain a single $\sim 5-\mathrm{kDa}$ band (Fig. $3 \mathrm{e}$ and Supplementary Fig. 7c), the N-terminal sequence of which matched that of stomagen (Supplementary Fig. $7 \mathrm{~d})$. Treatment with the purified stomagen for 3 days induced stomatal formation of Arabidopsis plants (Fig. 3f). We also used chemically synthesized stomagen (45 amino acids residues). Both the synthetic and recombinant stomagens increased stomatal density dose-dependently at concentrations from $300 \mathrm{nM}$ to $10 \mu \mathrm{M}$ (Fig. 3g). The induction of stomatal formation was suppressed by adding anti-stomagen antibody (Fig. 3g). These results demonstrate that stomagen is a stomata-inducing factor.

The stomatal lineage is triggered by SPEECHLESS $(S P C H)^{13,14}$, which is a basic helix-loop-helix (bHLH) type transcriptional factor. Both overexpression of STOMAGEN in a spch mutant (three lines of T1 plants) and application of purified stomagen to a spch mutant $(n=20)$ failed to induce stomatal formation (Fig. 4a). These results indicate that the stomata-inducing activity of stomagen is dependent on the SPCH pathway. SPCH regulates the expressions of both the receptor-like protein TMM and its putative ligands EPF1 and EPF2 (refs 6, 13, 14).

TMM acts negatively in leaves but positively in stems $^{16}$, whereas EPF1 and EPF2 act negatively in both organs ${ }^{4,5}$. Surprisingly, $44.8 \pm 16.7$-fold overexpression of STOMAGEN in a tmm mutant background failed to increase stomatal density in either stems or leaves (ten independent T2 lines; Fig. $4 \mathrm{~b}$ and Supplementary Fig. 8). Gene silencing of STOMAGEN in tmm did not affect the stomatal density of tmm leaves (ten independent T2 lines; Fig. $4 \mathrm{~b}$ and Supplementary Fig. 8). These results indicate that STOMAGEN requires TMM for positive 
regulation of stomatal development. EPF1 and EPF2 are thought to negatively regulate stomatal development by interacting with TMM as ligands. It is possible that stomagen competes with either EPF1 or EPF2 for the same receptor, TMM.

We silenced STOMAGEN in epf mutants and determined two indices: stomatal density and non-stomatal cell density (density of epidermal cells other than stomata). Stomatal density was higher in each epf mutant than in the wild type and the elevation of stomatal density was reduced in STOMAGEN gene silencing lines (Fig. 4c and Supplementary Fig. 9). This result suggests that STOMAGEN regulates the stomatal density in an EPF-independent manner. On the other hand, non-stomatal cell density was much higher in epf2 mutants than in the wild type (Fig. 4d), consistent with the role of EPF2 as a negative regulator of the production of stomatal lineage cells ${ }^{6,17}$. Gene silencing of STOMAGEN did not reduce the high density of non-stomatal cells in epf2 (11 independent T2 lines), although it reduced non-stomatal cell density in the wild type (14 independent T2 lines) (Fig. $4 \mathrm{~d}$ and Supplementary Fig. 9). This result suggests that STOMAGEN regulates the production of stomatal lineage cells in an EPF2-dependent manner. It seems that STOMAGEN has two functions: it regulates the production of stomatal lineage cells EPF2-dependently, and the differentiation of stomatal lineage cells to stomata independent of EPF1 and EPF2.

Taken together, three putative signalling factors - stomagen, EPF1 and EPF2-regulate stomatal development through the common receptor-like protein TMM. In addition to these signalling factors, SDD1 is known to act upstream of $T M M^{9}$. SDD1 has been thought to negatively regulate stomatal development by proteolytically processing some negative precursor factors ${ }^{9,18}$. However, SDD1 is genetically independent of EPF1 and $E P F 2^{4-6}$. Another possibility is that SDD1 exerts its negative effect on stomatal development by degrading stomagen, a positive regulator.

Our findings show that stomatal development is regulated by two classes of signals which have opposing effects: a positive signal, stomagen, and the negative signals, EPF1 and EPF2. Such a bi-directional signalling system would enable plants to control stomatal density more precisely. Our results also show that mesophyll-derived stomagen positively regulates the differentiation of stomatal lineage cells into stomata in the epidermis. This inter-tissue signalling would provide a conceptual advancement: stomatal density is optimized by photosynthetic tissues for efficient uptake of CO2. Stomagen could be a useful tool, either through genetic engineering or by spraying, for developing crops and trees with high stomatal densities that have a high absorption capacity for $\mathrm{CO}_{2}$.

\section{METHODS SUMMARY}

\section{Plant materials and phenotypic analysis}

Arabidopsis thaliana accession Columbia-0 (CS60000) was used as the wild type. Mutants used are tmm (SALK_011958), epf1 (SALK_137549), epf2 (SALK_047918) and spch (SAIL_36_B6). Stomata stained with Safranin-O $\left(1 \mu \mathrm{g} \mathrm{ml}^{-1}\right)$ were inspected with a microscope (Axioskop 2, Zeiss).

\section{Plasmid constructions}

Plant binary vectors based on Gateway cloning technology (Invitrogen) were used. Two artificial microRNAs for STOMAGEN were designed as described $^{19}$. The promoter $(2 \mathrm{~kb})$ and coding region of genomic DNA of STOMAGEN were cloned into pENTR/D-TOPO (Invitrogen). The DNA fragments were transferred into pBGWFS7 for promoter analysis and into either $\mathrm{pB} 2 \mathrm{GW} 7$ or $\mathrm{pH} 2 \mathrm{GW} 7$ for overexpression.

\section{Immunoprecipitation}

Extracts from transgenic plants expressing STOMAGEN-Venus (3 $\mathrm{g}$ fresh weight) were subjected to immunoprecipitate at $4{ }^{\circ} \mathrm{C}$ with $200 \mu \mathrm{l}$ of anti-GFP microbeads ( $\mu$ MACS GFP tag protein isolation kit, Milteny Biotech).

\section{Recombinant stomagen}

Stomagen was produced in tobacco-cultured BY-2 cells by using the Tomato mosaic virus based expression vector and the inducible virus infection system $^{20}$. The BY-2 medium was ultra-centrifuged at $1,000,000 \mathrm{~g}$ for $1 \mathrm{~h}$ and filtered through a $0.22-\mu \mathrm{m}$ filter (Millex). Filtrate was charged to a reverse-phase HPLC column ( $\mu$ RPC C2/C18 SP4/6) and washed with 5\% methanol and $0.5 \%$ TFA. Elution was conducted with $90 \%$ methanol and $0.5 \%$ TFA. Each fraction $(1 \mathrm{ml})$ was concentrated up to approximately $100 \mu 1$.

\section{Stomata induction assay}

Stomagen was applied to Arabidopsis seedlings at 2 days after germination that germinated in B5 sterilized liquid medium. After a 3-day incubation at $22{ }^{\circ} \mathrm{C}$, abaxial epidermis of cotyledons was inspected with a confocal microscope to determine stomatal densities.

Received 9 June; accepted 17 November 2009; Published online 9 December 2009.

1. Hetherington, A. M. \& Woodward, F. I. The role of stomata in sensing and driving environmental change. Nature 424, 901-908 (2003). 
2. Nadeau, J. A. \& Sack, F. D. Stomatal development in Arabidopsis. In The Arabidopsis Book (eds Someville, C. \& Meyerowitz, E) doi:10.1199/tab.0066 (American Society of Plant Biologists, 2002).

3. Nadeau, J. A. \& Sack, F. D. Control of stomatal distribution on the Arabidopsis leaf surface. Science 296, 1697-1700 (2002).

4. Hara, K., Kajita, R., Torii, K. U., Bergmann, D. C. \& Kakimoto, T. The secretory peptide gene EPF1 enforces the stomatal one-cell-spacing rules. Genes Dev. 21, 1720-1725 (2007).

5. Hunt, L. \& Gray, J. E. The signaling peptide EPF2 controls asymmetric cell divisions during stomatal development. Curr. Biol. 19, 864-869 (2009).

6. Hara, K. et al. Epidermal cell density is autoregulated via a secretory peptide, EPIDERMAL PATTERNING FACTOR 2 in Arabidopsis leaves. Plant Cell Physiol. 50, 1019-1031 (2009).

7. Bergmann, D. C. Integrating signals in stomatal development. Curr. Opin. Plant Biol. 7, 26-32 (2004).

8. Shpak, E. D., McAbee, J. M., Pillitteri, L. J. \& Torii, K. U. Stomatal patterning and differentiation by synergistic interactions of receptor kinases. Science 309, 290-293 (2005).

9. Berger, D. \& Altmann, T. A subtilisin-like serine protease involved in the regulation of stomatal density and distribution in Arabidopsis thaliana. Genes Dev. 14, 1119-1131 (2000).

10. Nadeau, J. A. Stomatal development: new signals and fate determinants. Curr. Opin. Plant Biol. 12, 29-35 (2009).

11. Obayashi, T., Hayashi, S., Saeki, M., Ohta, H. \& Kinoshita, K. ATTED-II provides coexpressed gene networks for Arabidopsis. Nucleic Acids Res. 37, D987-D991 (2009).

12. Sachs, T. The development of spacing patterns in the leaf epidermis. In Clonal Basis of Development 161-182 (Academic Press, 1987).

13. MacAlister, C. A., Ohashi-Ito, K. \& Bergmann, D. C. Transcription factor control of asymmetric cell divisions that establish the stomatal lineage. Nature 445, 537-540 (2007).

14. Pillitteri, L. J., Sloan, D. B., Bogenschutz, N. L. \& Torii, K. U. Termination of asymmetric cell division and differentiation of stomata. Nature 445, 501-505 (2007).

15. Serna, L., Torres-Contreras, J. \& Fenoll, C. Specification of stomatal fate in Arabidopsis: evidences for cellular interactions. New Phytol. 153, 399-404 (2002).
16. Geisler, M., Yang, M. \& Sack, F. D. Divergent regulation of stomatal initiation and patterning in organ and suborgan regions of the Arabidopsis mutants too many mouths and four lips. Planta 205, 522-530 (1998).

17. Geisler, M., Nadeau, J. \& Sack, F. D. Oriented asymmetric divisions that generate the stomatal spacing pattern in Arabidopsis are disrupted by the too many mouths mutation. Plant Cell 12, 2075-2086 (2000).

18. von Grolla, U., Bergera, D., \& Altmann. T. The subtilisin-like serine protease SDD1 mediates cell-to-cell signaling during Arabidopsis stomatal development. Plant Cell. 14, 1527-39 (2002).

19. Schwab, R., Ossowski, S., Riester, M., Warthmann, N. \& Weigel, D. Highly specific gene silencing by artificial microRNAs in Arabidopsis. Plant Cell 18, 1121-1133 (2006).

20. Dohi, K., Tamai, A. \& Mori, M. Insertion in the coding region of the movement protein improves stability of the plasmid encoding a tomato mosaic virus-based expression vector. Arch. Virol. 153, 1667-1675 (2008).

Supplementary Information is linked to the online version of the paper at www.nature.com/nature.

Acknowledgements We thank $T$. Nakagawa for donating the TMM::GFP seeds; K. Yamada for his technical support of quantitative PCR; and Y. Nakata for her technical support of in situ hybridization. We thank J. Raymond for reading and editing the manuscript. We thank the ABRC for providing seeds of Arabidopsis T-DNA insertion lines. This work was supported by Grants-in-Aid for Scientific Research (no. 16085203 and 17107002) from the Ministry of Education, Culture, Sports, Science and Technology (MEXT) of Japan, by the Global Center of Excellence Program 'Formation of a Strategic Base for Biodiversity and Evolutionary Research: from Genome to Ecosystem' of MEXT, and by Japan Science and Technology Agency (JST).

Author Contributions T.S. performed in silico screening to identify STOMAGEN. S.S.S. established the STOMAGEN-RNAi lines, performed genetic interaction experiments and other experiments including antibody production and in situ hybridization. S.S.S. also purified recombinant stomagen, refolded chemically synthesized stomagen, and evaluated their stomata inducing activities. Y.I. developed the STOMAGEN-OX and pSTOMAGEN::GUS lines. A.T. and M.M. produced stomagen in tobacco-cultured cells by using their ToMV-expression system. K.O. conducted MS analysis of STOMAGEN-Venus. I.H.-N. and T.S. designed this project and supervised. S.S.S., T.S. and I.H.-N. wrote the paper with input from co-authors. 
Author Information Reprints and permissions information is available at www.nature.com/reprints. The authors declare no competing financial interests. Correspondence and requests for materials should be addressed to I.H.-N. (ihnishi@gr.bot.kyoto-u.ac.jp).

\section{METHODS}

\section{In silico screening}

The genes co-expressed with a set of TMM, SDD1 and EPF1 were searched by using ATTED-II (http://atted.jp/). The program used was NetworkDrawer in the tool section of ATTED-II. The procedure was composed of three steps: first was to select 'Execute' and 'MR-rank method' ${ }^{\text {'1 }}$ and 'top 300 genes in 22,263 genes' in Function 3; second was to input three AGI codes of At1g80080 (TMM), At1g04110 (SDD1) and At2g20875 (EPF1); third was to submit the codes.

\section{Plant materials and growth conditions}

Arabidopsis accession Columbia-0 (CS60000) was used as the wild type. Plants were initially grown on GM plates (MS salts, 1\% sucrose, 0.5\% MES-KOH, pH 5.7 and $0.5 \%$ Gellan gum) under continuous light at $22{ }^{\circ} \mathrm{C}$ for $2-3$ weeks before being transferred to soil. The mutants used were as follows: tmm (SALK_011958), epf1 (SALK_137549), epf2 (SALK_047918) and spch (SAIL 36_B6). Their T-DNA inserts were confirmed using primers designed by iSECT tools (Supplementary Table 2). The pTMM::GFP line was provided by T. Nakagawa ${ }^{21}$. Three types of STOMAGEN-silenced lines (STOMAGEN-RNAi) were generated (see below). STOMAGEN-RNAi generated with ami-A was used except for Supplementary Fig. 3.

\section{Plasmid construction}

Plant binary vectors based on Gateway cloning technology (Invitrogen) were used for most manipulations. DNA fragments for STOMAGEN overexpression and silencing by dsRNA were PCR-amplified from genomic DNA. An upstream region $(2 \mathrm{~kb})$ from the start codon for STOMAGEN was used as a promoter for STOMAGEN expression analysis. Translational fusions for STOMAGEN were constructed by joining three independently amplified PCR fragments, namely Venus with 4 glycines at its C terminus (Venus), the signal peptide for pumpkin $2 \mathrm{~S}$ albumin $^{22}$ (SP), and the STOMAGEN open reading frame without its stop codon (STOMAGEN). The two independent artificial microRNAs for STOMAGEN (ami-A and ami-B) were designed according to ref. 19. The PCR products were cloned into $\mathrm{pENTR/D-TOPO}$ (Invitrogen) before being transferred to pBGWFS7 for promoter analysis, to either $\mathrm{pB} 2 \mathrm{GW} 7$ or $\mathrm{pH} 2 \mathrm{GW} 7$ for overexpression, or to $\mathrm{pB} 2 \mathrm{GWI}(2) \mathrm{WG} 7$ for dsRNA.
Plants were stably transformed by using standard protocols for Agrobacterium (strain GV3101)-mediated transformation. Transgenic lines were selected on GM plates containing $10 \mathrm{mg} \mathrm{l}^{-1}$ glufosinate-ammonium (Sigma) or $10 \mathrm{mg} \mathrm{l}^{-1}$ hygromycin (Sigma). For expression of stomagen in Escherichia coli, a DNA fragment coding stomagen was PCR-amplified and then cloned into pET32-derived vector ${ }^{23}$ (Novagen).

\section{Phenotype analysis}

Phenotypic analysis was performed using at least seven individual plants of each of ten independent T2 lines $(n>70)$ except for sph STOMAGEN-OX (three lines of T1 plant). Plant organs, including $23 \mathrm{DAG}$ cotyledons, 23 DAG first leaves, fully expanded second internodes, mature fruits and anther of flowering buds in the same size were collected. The organs were fixed in ethanol:acetic acid (9:1) for over $7 \mathrm{~h}$ and cleared in chloral hydrate solution (chloral hydrate:water:glycerol (8:2:1, w/v/w)). After removal of chloral hydrate, stomata were stained with $1 \mu \mathrm{g}$ $\mathrm{ml}^{-1}$ Safranin-O. Leaf epidermis was examined under a microscope at $\times 20$ (Axioskop 2 plus system; Zeiss) with a CCD camera (model VB-7010; Keyence). Four square-areas of $0.22 \mathrm{~mm}^{2}$ were analysed for quantification of stomatal density and non-stomatal cell density. Statistical analysis was conducted using $\mathrm{R}$ statistical computing software (http://www.R-project.org). We conducted Kruskal-Wallis test for Fig. 4b, and two-tailed Student's $t$-test for Figs 3d, g and 4c, d.

\section{RNA isolation and quantitative RT-PCR}

Total RNA was extracted from 12th leaves of wild type, mutants and transgenic lines (23 DAG) as described previously ${ }^{24}$. Real-time PCR was performed using the 7500 Fast Real-Time PCR system (Applied Biosystems) and the TaqMan gene expression assay kit (Applied Biosystems) according to the manufacturer's instructions. The assay identifiers were At02219575 g1 for STOMAGEN and At02270958 gH for ACTIN8. We used the threshold cycle method for relative quantification ${ }^{25}$.

\section{GUS staining}

GUS staining was performed as described previously ${ }^{26}$, except that the samples were fixed with $90 \%$ acetone at $4{ }^{\circ} \mathrm{C}$ for $7-10 \mathrm{~h}$.

\section{In situ hybridization}

In situ hybridization was performed as described previously ${ }^{24}$. Labelled probes were prepared from the coding region of the STOMAGEN cDNA (306 bp).

\section{Confocal fluorescent microscopy}

The fluorescent images were inspected under a confocal laser scanning microscope (model LSM510 
META; Zeiss) by using the 488-nm and 544-nm lines of a $40-\mathrm{mW} \mathrm{Ar} / \mathrm{Kr}$ laser. We used filter sets for Venus, GFP and FM1-43 fluorescences (an excitation filter of BP450-490, a dichroic mirror of FT510, and a barrier filter of BP515-565; Zeiss) and for FM4-64 fluorescence (an excitation filter of BP515-560, a dichroic mirror of FT510, and a barrier filter of BP515-565; Zeiss).

\section{Expression of recombinant proteins by using tobacco-cultured BY-2 cells}

The recombinant proteins including stomagen, STOMAGEN-GFP and EPF1-GFP were produced in cultured BY-2 cells using the tomato mosaic virus (ToMV)-based expression vector and the inducible virus infection system (IVIS) ${ }^{20}$. The ToMV vector for expression of each recombinant protein was constructed using pBICER8-ToMV-C0.3-HuIFN $\gamma$-SRz22 by replacing the IFN $\gamma$ gene with the cDNA encoding each of stomagen, STOMAGEN-GFP and EPF1-GFP. GFP cDNA was PCR-amplified and inserted into the $3^{\prime}$ end of STOMAGEN or EPF1 gene of ToMV-STOMAGEN or ToMV-EPF1 vectors to produce the constructs. These constructs were introduced to the transgenic BY-2 cells expressing the estrogen-activatable transcription factor XVE. Induction by $\beta$-estradiol was performed essentially according to ref. 20 . The cell cultures were centrifuged for $3 \mathrm{~min}$ at 800 r.p.m. The supernatant containing the secreted recombinant stomagen was subjected to purification (see below). The pellets containing STOMAGEN-GFP or EPF1-GFP were subjected to immunoblot analysis.

\section{Purification of recombinant stomagen}

Culture medium of the BY-2 cells expressing stomagen was ultra-centrifuged at $1,000,000 \mathrm{~g}$ for $1 \mathrm{~h}$ and the supernatant was filtered through a $0.22-\mu \mathrm{m}$ filter (Millex). The filtrate was applied to a reverse-phase HPLC column ( $\mu$ RPC C2/C18 SP4/6). After washing the column with a solution of $5 \%$ methanol and $0.5 \%$ TFA, elution was conducted with a linear gradient of methanol (5\% to $90 \%)$. Each fraction $(1 \mathrm{ml})$ was collected and then concentrated to approximately $100 \mu$ l by evaporation.

\section{Specific antibody}

Stomagen was expressed in E. coli strain BL21. The recombinant protein was purified by affinity chromatography using a Hi-Trap chelating column (GE Healthcare) followed by cation-exchange chromatography using a H-SP column (GE healthcare). The purified preparation was injected into a rabbit as described previously ${ }^{26}$. To check this, we did immunoblots of STOMAGEN-GFP and EPF1-GFP with either the antibody raised against stomagen or anti-GFP antibody. We confirmed that the antibody against stomagen recognized STOMAGEN-GFP but not EPF1-GFP, whereas anti-GFP antibody recognized both (Supplementary Fig. 10).

\section{Immunoprecipitation}

Immunoprecipitation was conducted by using the GFP tag protein isolation kit ( $\mu$ MACS; Milteny Biotech). Extract from wild type or STOMAGEN-Venus plants (7 $\mathrm{g}$ fresh weight) in $5 \mathrm{ml}$ of $50 \mathrm{mM}$ Tris- $\mathrm{HCl}, \mathrm{pH} 7.5$, $50 \mathrm{mM} \mathrm{NaCl}$, and 1\% CHAPS was incubated with $200 \mu \mathrm{l}$ of anti-GFP microbeads at $4{ }^{\circ} \mathrm{C}$. The beads were trapped with magnetic columns and the bound proteins were eluted with a loading buffer of the kit.

\section{Immunoblot}

Immunoblot was basically performed as described previously ${ }^{24}$. Anti-stomagen antibody was diluted $1: 1,000 \quad(\mathrm{v} / \mathrm{v})$. Horseradish peroxidase-conjugated goat antibody against rabbit IgG (diluted 5,000-fold, NA934, GE Healthcare) was used as the secondary antibody.

\section{$\mathrm{N}$-terminal sequencing}

The immunoprecipitated samples were subjected to SDS-PAGE followed by blotting on PVDF membranes (Immobilon-P, Millipore) and then subjected to either Coomassie blue (CBB) staining or immunostaining. The CBB-stained band that corresponded to the positive signal on the immunoblot was subjected to $\mathrm{N}$-terminal sequencing analysis with an automatic peptide sequencer (Procise 492cLC, Applied Biosystems), as described previously ${ }^{22}$.

\section{Refolding of synthetic stomagen}

Chemically synthesized peptides (Invitrogen, $0.5 \mathrm{mg} \mathrm{ml}^{-1}$ ) that were dissolved in $20 \mathrm{mM}$ Tris- $\mathrm{HCl}$, $\mathrm{pH} 8.8$, and $50 \mathrm{mM} \mathrm{NaCl}$ were dialysed (Spectra/Por3 MWCO, 3,500; Spectrum Laboratories) for 1 day at $4{ }^{\circ} \mathrm{C}$ against $0.5 \mathrm{mM}$ glutathione (reduced and oxidized forms, Wako) and $200 \mathrm{mM}$ L-arginine (Sigma) at $\mathrm{pH} 8.0$, and were further dialysed three times against $20 \mathrm{mM}$ Tris- $\mathrm{HCl}, \mathrm{pH} 8.8$, and $50 \mathrm{mM}$ $\mathrm{NaCl}$ for 1.5 days to remove glutathione.

\section{Mass spectrometry}

Mass spectrometric identification was performed as described $^{27}$. Proteins were separated by SDS-PAGE followed by silver staining. The respective bands were excised separately and then subjected to the in-gel digestions with either trypsin or lysyl endopeptidase (Promega) in a buffer containing $50 \mathrm{mM}$ ammonium bicarbonate, $\mathrm{pH} 8.0$, and $2 \%$ acetonitrile at $37^{\circ} \mathrm{C}$ overnight. The digests were subjected to matrix-assisted laser desorption/ionization time-of-flight mass spectrometry (MALDI-TOF/MS) 
with an ultraflex TOF/TOF (MALDI-TOF/MS, Bruker Daltonics).

\section{Stomata induction assay}

Stomagen was applied to 2 DAG Arabidopsis plants that had germinated in B5 sterilized liquid medium. After further 3 days of incubation at $22^{\circ} \mathrm{C}$, stomatal densities of abaxial cotyledon were determined by inspecting with a confocal microscope. An effect of ethylene on stomatal development in liquid medium with or without stomagen was evaluated by using an ethylene action inhibitor, silver thiosulphate. We confirmed that stomata-inducing activity of stomagen was independent on ethylene.

21. Kono, A. et al. The Arabidopsis D-type cyclin CYCD4 controls cell division in the stomatal lineage of the hypocotyl epidermis. Plant Cell 19, 1265-1277 (2007).

22. Hara-Nishimura, I., Takeuchi, Y., Inoue, K. \& Nishimura, M. Vesicle transport and processing of the precursor to $2 \mathrm{~S}$ albumin in pumpkin. Plant J. 4, 793-800 (1993).
23. Shimada, T. et al. AtVPS29, a putative component of a retromer complex, is required for the efficient sorting of seed storage proteins. Plant Cell Physiol. 47, 1187-1194 (2006).

24. Kunieda, T. et al. NAC family proteins NARS1/NAC2 and NARS2/NAM in the outer integument regulate embryogenesis in Arabidopsis. Plant Cell 20, 2631-2642 (2008).

25. Livak, K. J. \& Schmittgen, T. D. Analysis of relative gene expression data using real-time quantitative PCR and the $2^{-\Delta \Delta C(\mathrm{~T})}$ method. Methods 25, 402-408 (2001).

26. Kinoshita, T. et al. Vacuolar processing enzyme is up-regulated in the lytic vacuoles of vegetative tissues during senescence and under various stressed conditions. Plant J. 19, 43-53 (1999).

27. Jensen, O. N., Podtelejnikov, A. \& Mann, M. Delayed extraction improves specificity in database searches by matrix-assisted laser desorption/ionization peptide maps. Rapid Commun. Mass Spectrom. 10, 1371-13 8 (1996). 
a

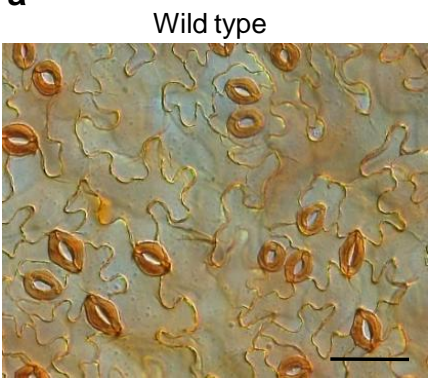

STOMAGEN-RNAi10

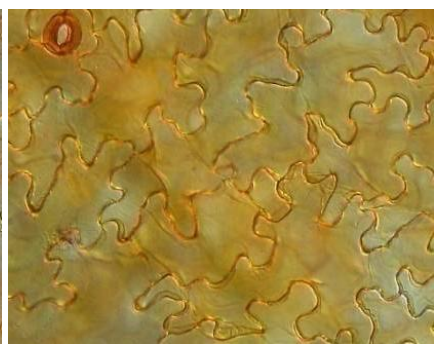

STOMAGEN-OX10

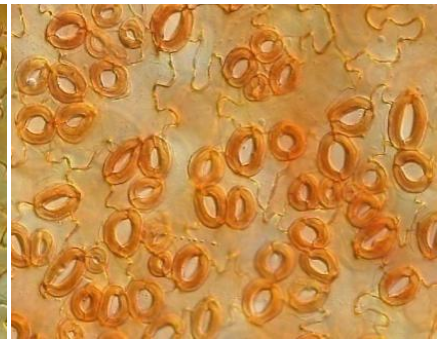

b

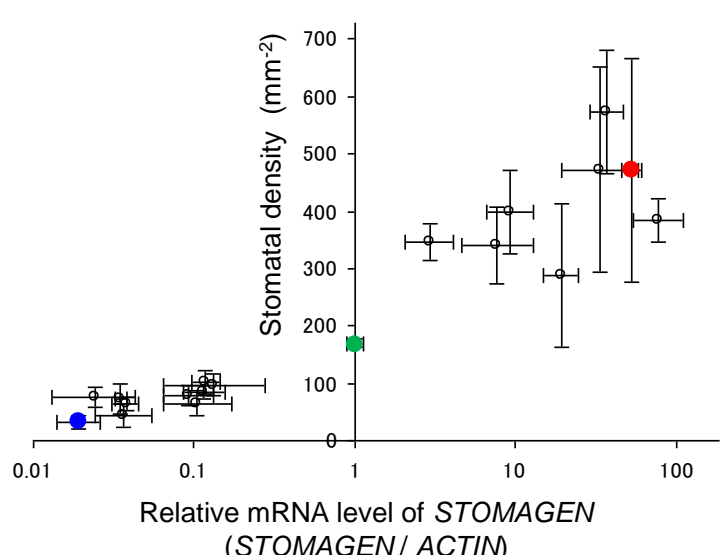

Wild type

- STOMAGEN-RNAi10

STOMAGEN-OX10

C

\begin{tabular}{cccc}
\hline & STOMAGEN mRNA & Stomatal density $\left(\mathrm{mm}^{-2}\right)$ & Stomatal index $(\%)$ \\
\hline WT & $1.0 \pm 0.11$ & $174.4 \pm 24.5$ & $32.9 \pm 4.45$ \\
\hline STOMAGEN-RNAi & $0.07 \pm 0.04$ & $71.9 \pm 15.1$ & $17.4 \pm 5.19$ \\
\hline STOMAGEN-OX & $30.1 \pm 25.8$ & $408.9 \pm 91.5$ & $50.9 \pm 12.1$ \\
\hline
\end{tabular}

Figure 1. STOMAGEN positively regulates stomatal development.

a, Differential interference contrast (DIC) images of the abaxial epidermis of mature first leaves of wild type, a STOMAGEN-silenced line (STOMAGEN-RNAi10) and a STOMAGEN-overexpressing line (STOMAGEN-OX10). Stomata were stained with Safranin-O. Scale bar, $50 \mu \mathrm{m}$. b. Correlation between stomatal density in mature first leaves and the relative mRNA level of STOMAGEN measured by real-time PCR. Green, blue and red dots correspond to wild type, STOMAGEN-RNAi10 and STOMAGEN-OX10. Error bars indicate s.d. c, STOMAGEN mRNA level, stomatal density and stomatal index in wild type, STOMAGEN-RNAi and STOMAGEN-OX. 

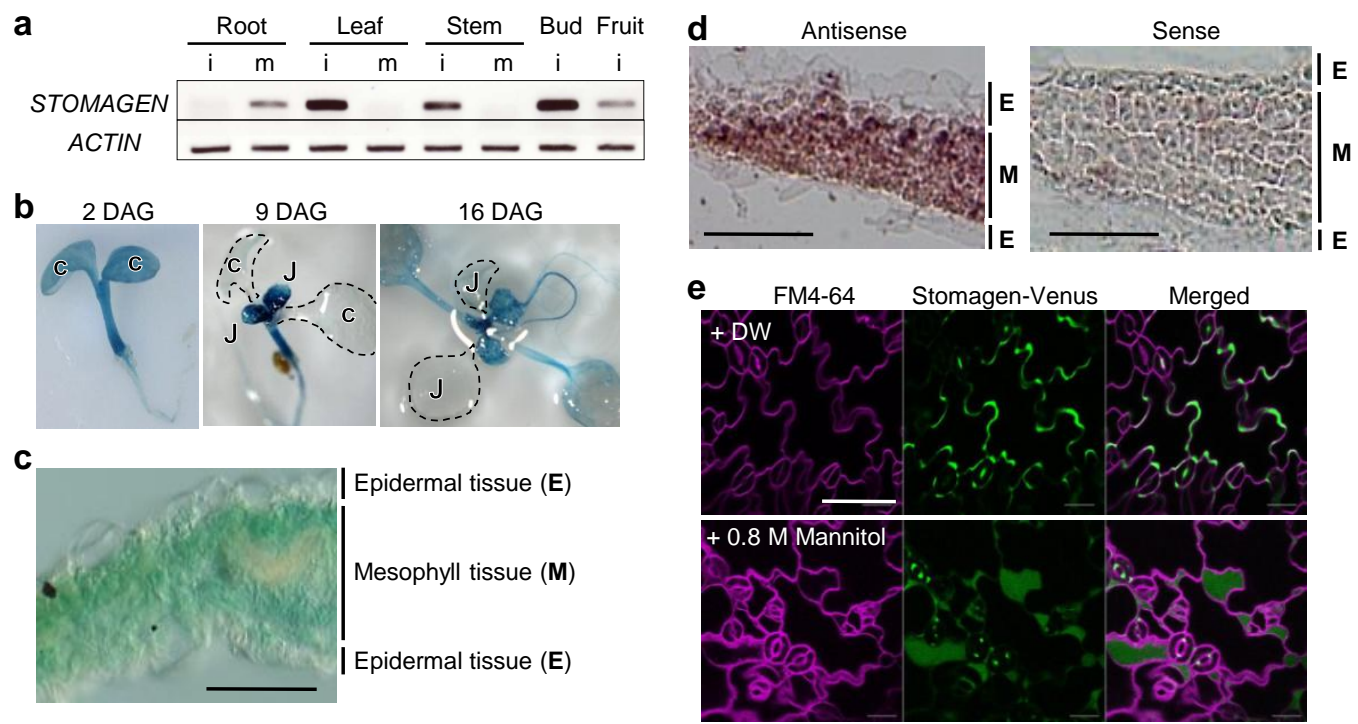

Figure 2. Stomagen is expressed in inner tissues of immature organs and secreted out of the cells to mediate inter-tissue signalling.

a, RT-PCR showing STOMAGEN mRNA levels in mature $(\mathrm{m})$ and immature (i) organs including roots, leaves, stems, buds and fruits. $A C T I N$ was used as an internal control. b, GUS staining of a pSTOMAGEN::GUS line at 2, 9 and 16 days after germination (DAG). C, cotyledons; J, juvenile leaves. c, A cross-section of the 9th leaf of an 18-DAG pSTOMAGEN::GUS plant showing GUS staining in mesophyll. d, In situ hybridization in leaf primordia with both antisense and sense STOMAGEN probes. e, Confocal images of abaxial sides of 3-DAG cotyledons stained with FM4-64 of a STOMAGEN-Venus line. Untreated cells in distilled water (DW) (upper) and plasmolysed cells in $0.8 \mathrm{M}$ mannitol (lower) are shown. All scale bars, $50 \mu \mathrm{m}$. 


\section{STOMAGEN}

MKHEMMN IKPRCIT I FFLLFALLLGN YVVOASR PRS IENTVSLLPOVHLLNS RRRHMIGSTA PTCTYNECRGCR YKCRAEOVPVEGNDP PNSA YHYRCVCHR signal peptide

propeptide

stomagen

b

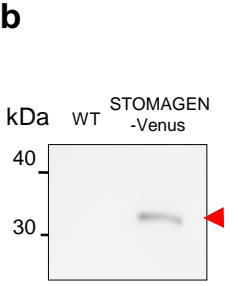

C
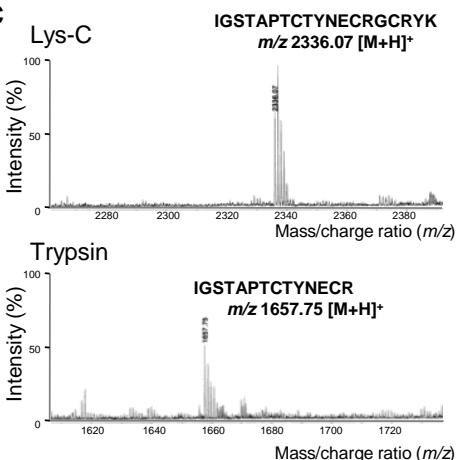

d
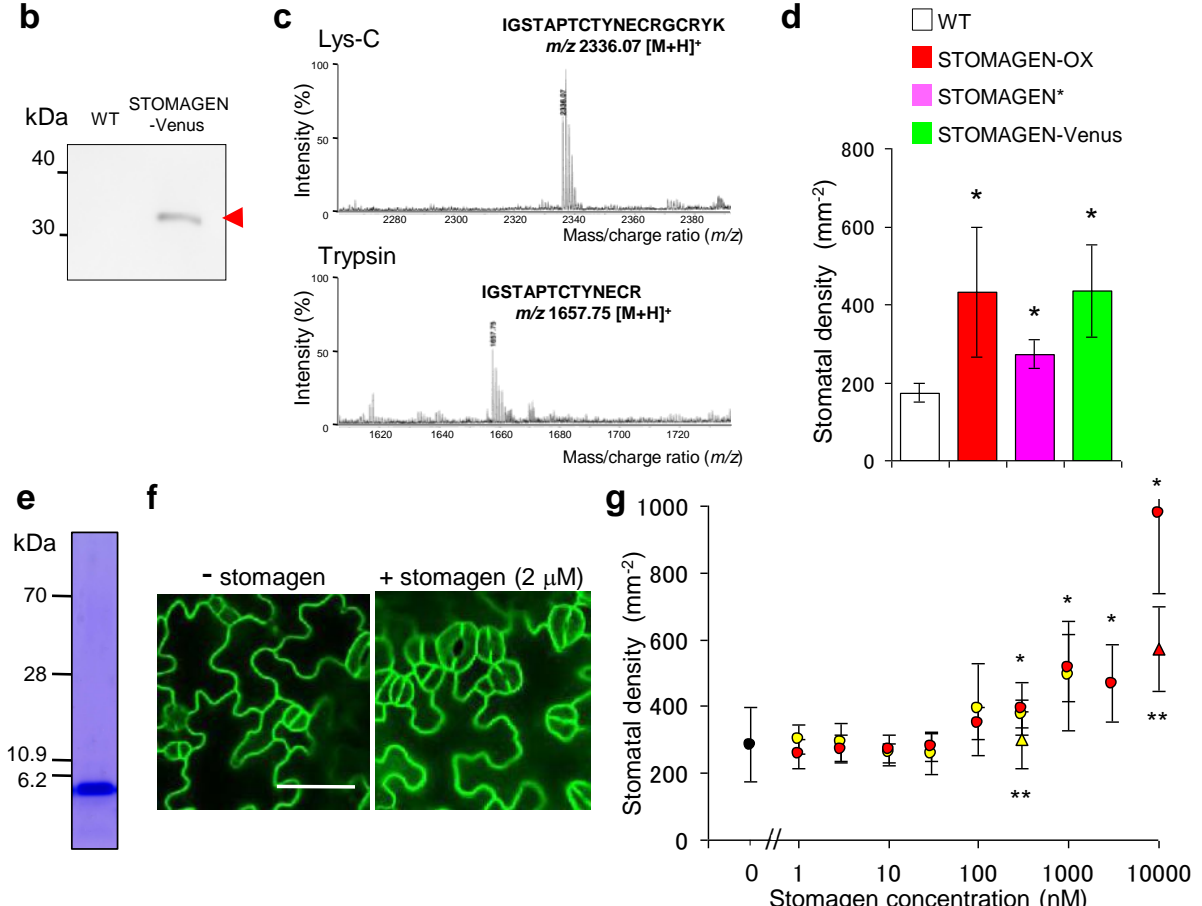

Figure 3. Stomagen, a 45-amino-acid cysteine-rich region of the STOMAGEN, is a mobile stomata-inducing factor.

a, STOMAGEN encodes a 102-amino-acid protein composed of a signal peptide (blue) that was predicted by PSORT (http://psort.ims.u-tokyo.ac.jp/), a propeptide (yellow) and stomagen (red). Asterisks indicate the determined N-terminal sequence of stomagen (see Supplementary Fig. 5). b, An immunoblot of a processed form of STOMAGEN-Venus in the transgenic leaves with anti-stomagen antibody. WT, wild type. c, Mass spectrometry of lysyl endopeptidase (top) and trypsin digests (bottom) of STOMAGEN-Venus showing the Nterminal peptides derived from stomagen. $\mathbf{d}$, Stomatal density of the abaxial epidermis of the first leaves of wild type, STOMAGEN-OX, STOMAGEN-Venus and a transformant expressing stomagen with a signal peptide at the $\mathrm{N}$ terminus (STOMAGEN ${ }^{\star}$ ). Asterisk, $P<0.01$ compared to wild type. e, Purified recombinant stomagen giving a single band on an SDS gel with Coomassie blue staining. Details of the purification and $\mathrm{N}$-terminal sequence data are in Supplementary Fig. 7. f, Confocal images of abaxial epidermis of cotyledons of an Lti6b-GFP line with or without $2 \mu \mathrm{M}$ recombinant stomagen treatment. Scale bar, $50 \mu \mathrm{m}$. $\mathbf{g}$, Dose dependency of stomata-inducing activity of stomagen. Yellow circles, recombinant stomagen; red circles, chemically synthesized stomagen; yellow triangle, recombinant stomagen with anti-stomagen antibody; red triangle, chemically synthesized stomagen with anti-stomagen antibody; black circle, no addition of stomagen. Asterisk, $P<0.01$ compared to no addition $(n=8)$; double asterisk, $P<0.01$ compared to additions with antibody $(n=8)$. Error bars indicate s.d. 
a
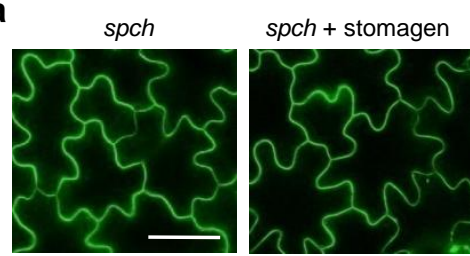

WT + stomagen

spch

spch STOMAGEN-OX
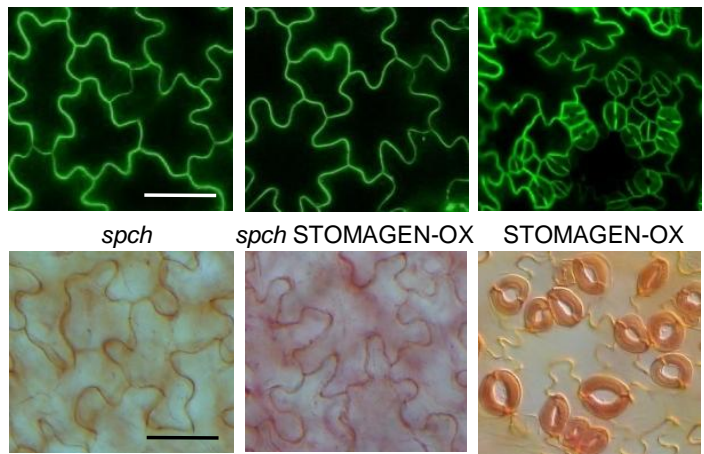

STOMAGEN-OX

b
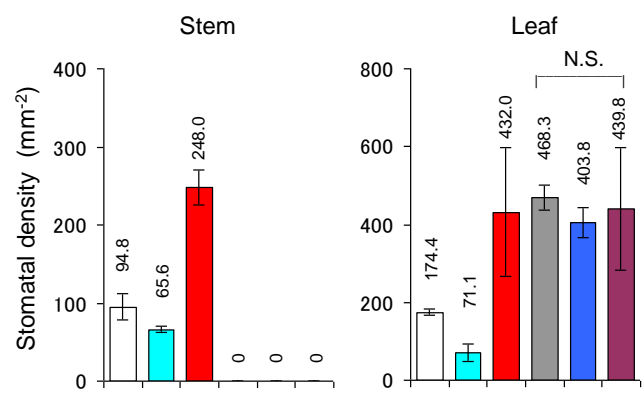

$\square$ WT STOMAGEN-RNAi

STOMAGEN-OX

tmm $\square \mathrm{tmm}$ STOMAGEN-RNAi $\square \mathrm{tmm}$ STOMAGEN-OX

C

d
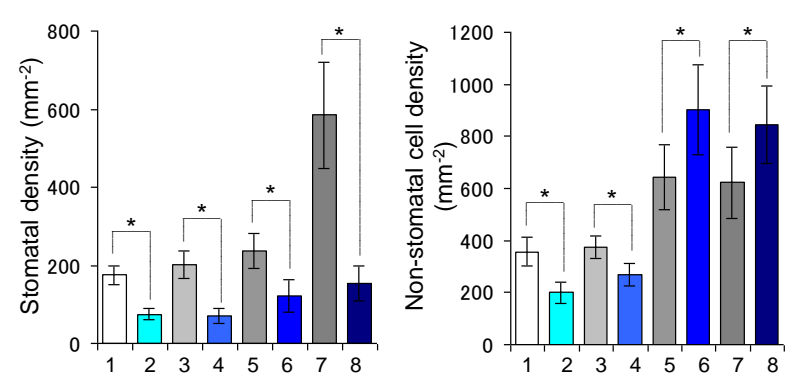

$\square(1)$ WT

(4) epf1 STOMAGEN-RNAi $\square$ (7) epf1 epf2

(2) STOMAGEN-RNAi

(5) epf2

(8) epf1 epf2 STOMAGEN-RNAi

(3) epf1

(6) epf2 STOMAGEN-RNAi

Figure 4. STOMAGEN regulates stomatal density TMM-dependently in combination with negative regulators EPF1 and EPF2

a, $\mathrm{SPCH}$-dependent stomatal inducing activity of stomagen. Confocal images of abaxial epidermis of cotyledons of wild type (WT) and spch with or without $2 \mu \mathrm{M}$ stomagen treatment are shown in the top panel. DIC images of abaxial epidermis of cotyledons of spch, STOMAGEN-OX in spch and STOMAGEN-OX are shown in the bottom panel. Scale bars, $50 \mu \mathrm{m}$. b, A genetic interaction between TMM and STOMAGEN. Stomatal density of stems (left) and an abaxial epidermis of the first leaves (right) of the indicated plants. NS, no significant difference among the three genotypes (tmm, tmm STOMAGEN-RNAi, tmm STOMAGEN-OX). c, d, A genetic interaction of STOMAGEN with each of EPF1 and EPF2. Stomatal density (c) and non-stomatal cell density (d) of abaxial epidermis of the first leaves of the indicated plants are shown. Asterisk, $P<0.01$. 


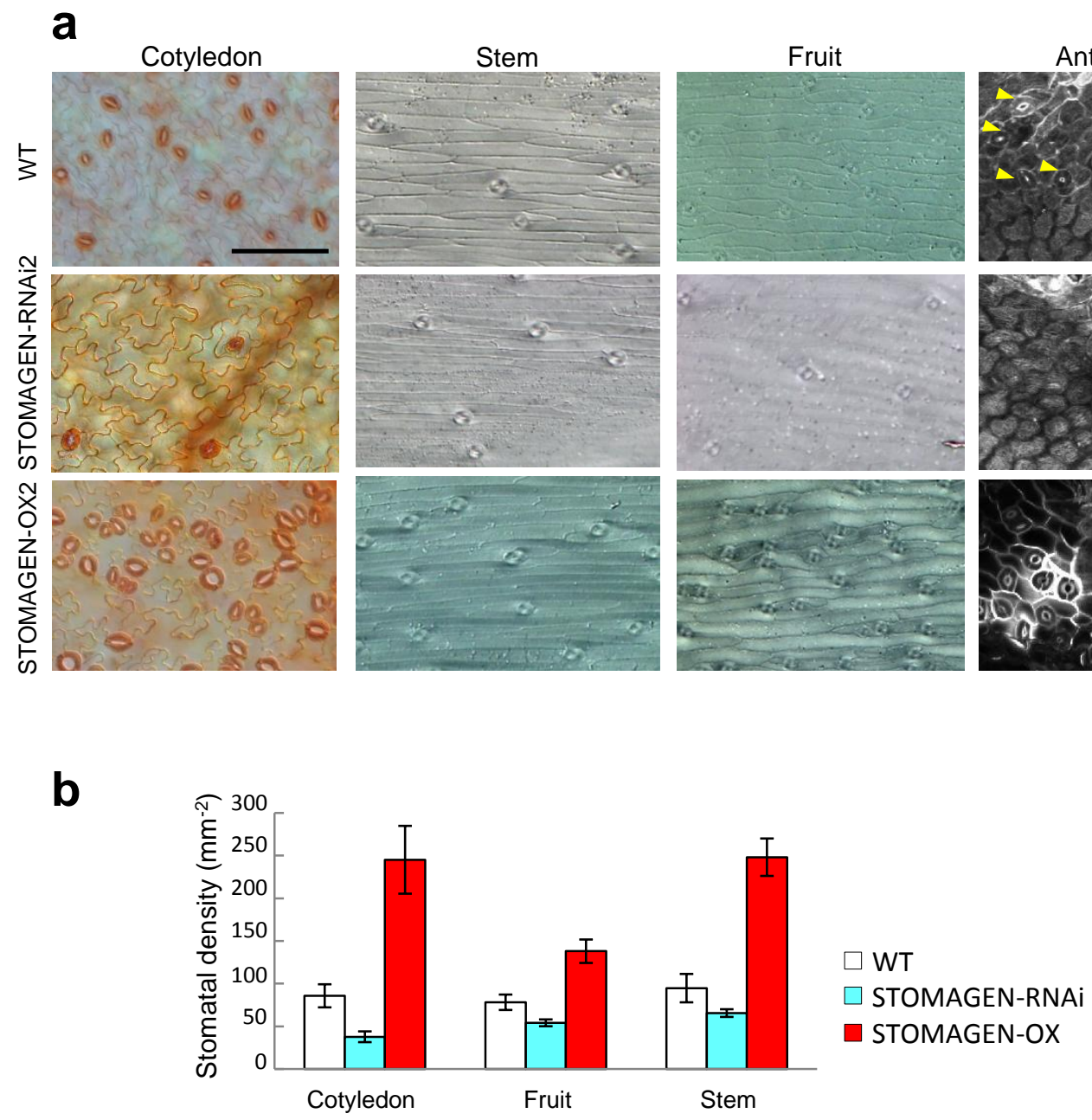

\section{Supplementary Figure 1. Stomatal phenotype of STOMAGEN-OX and STOMAGEN-} RNAi lines.

a, Epidermis of each of cotyledons, stems and fruits (DIC images) and of anthers (confocal images) of the wild type (WT), STOMAGEN-RNAi2 and STOMAGEN-OX2. Cell outlines in anthers were visualized with FM1-43. Yellow arrowheads indicate stomata of anthers. Bar, $100 \mu \mathrm{m}$.

b, Quantification of stomatal density in each organ with significant differences in ANOVA $(P<0.01)$. Error bars indicate S.D. 
a
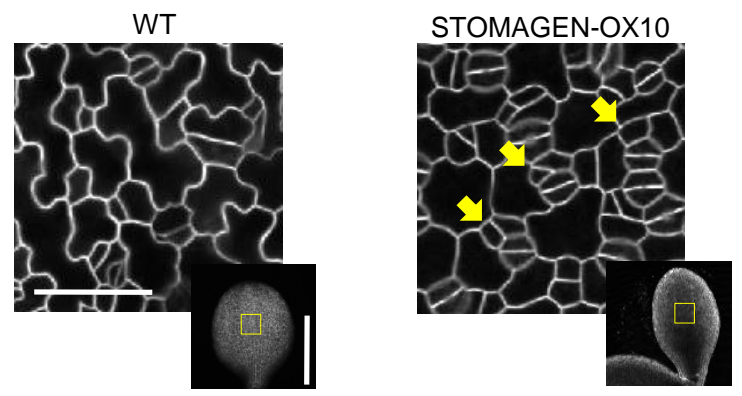

b

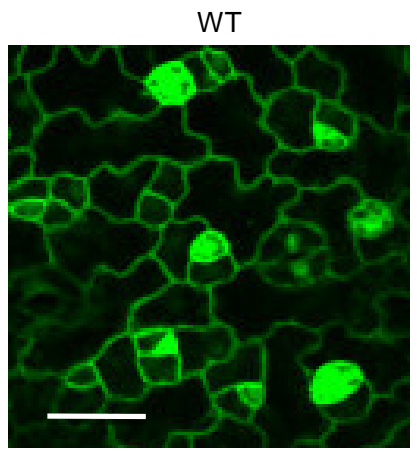

STOMAGEN-OX10

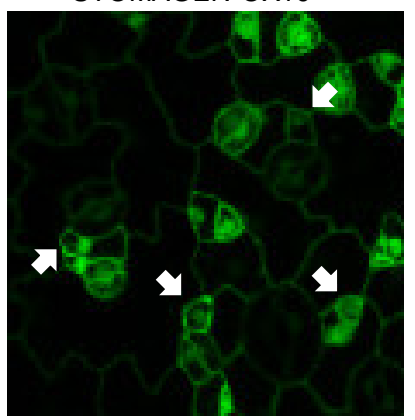

\section{Supplementary Figure 2. Abnormal meristemoids in STOMAGEN-OX.}

a, Abaxial sides of 2.5-DAG cotyledons of the wild type (WT) and STOMAGEN-OX plants that were stained with FM4-64 were inspected with a confocal microscope. The yellowboxed areas of the cotyledons are enlarged to obtain the confocal images. Arrows indicate abnormal asymmetric divisions. Horizontal bar, $50 \mu \mathrm{m}$; vertical bar, $500 \mu \mathrm{m}$.

b, Confocal images of pTMM::GFP in the epidermis of developing first leaves (5 DAG) of the wild type (WT) and STOMAGEN-OX plants. Abnormal meristemoids adjacent to guard cells are shown by arrows. Bar, $50 \mu \mathrm{m}$ 


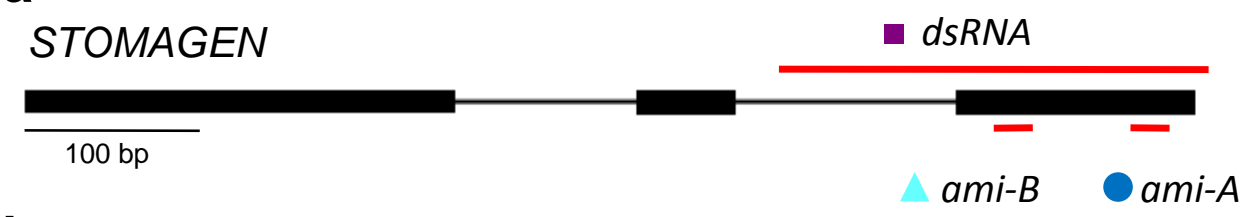

b
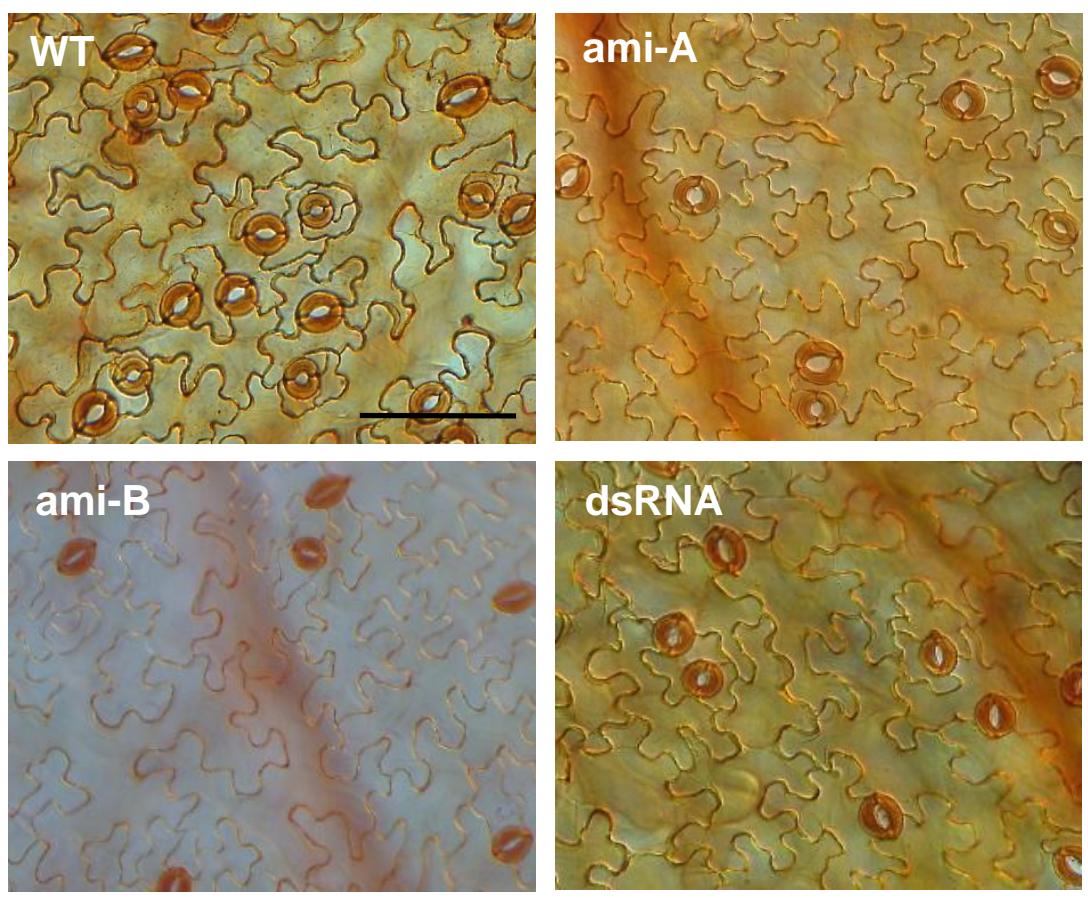

C

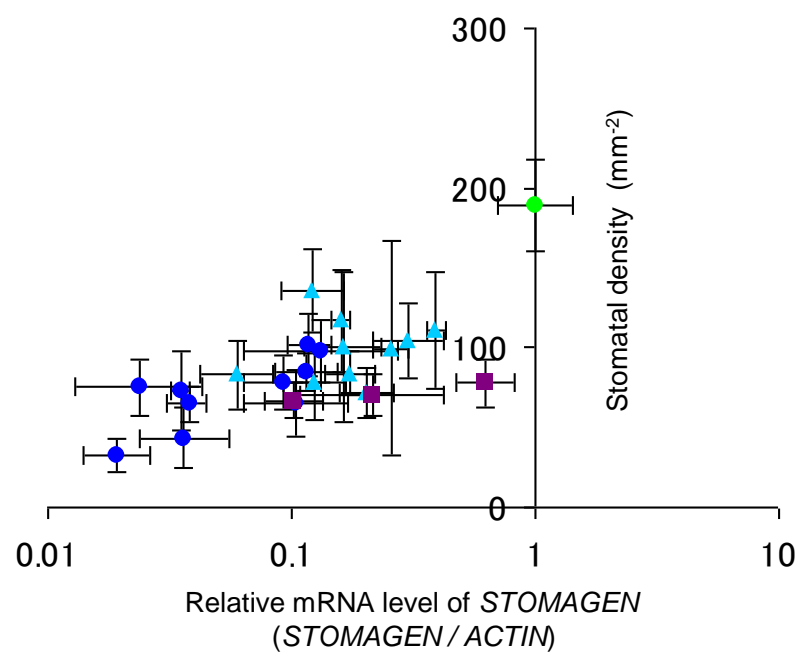

Supplementary Figure 3. Generation of three types of STOMAGEN-RNAi lines and correlation between stomatal density and the relative reduction level of STOMAGEN mRNA.

a, A schematic representation of three target sites of artificial microRNA-A (ami-A), ami-B and dsRNA for RNAi. The STOMAGEN gene is drawn with black boxes (exons) and lines (introns). b, DIC images of the abaxial sides of mature first leaves of STOMAGEN-gene silenced lines (STOMAGEN-RNAi) by using ami-A, ami-B, and dsRNA. Bar, $50 \mu \mathrm{m}$.

c, Correlation between stomatal density in mature first leaves in the STOMAGEN-RNAi lines and the relative reduction level of STOMAGEN mRNA measured by real-time PCR. Green circle, the wild type; blue circle, STOMAGEN-RNAi (ami-A); blue triangle, STOMAGEN-RNAi (ami-B); red square, STOMAGEN-RNAi (dsRNA). Error bars indicate S.D. 
a
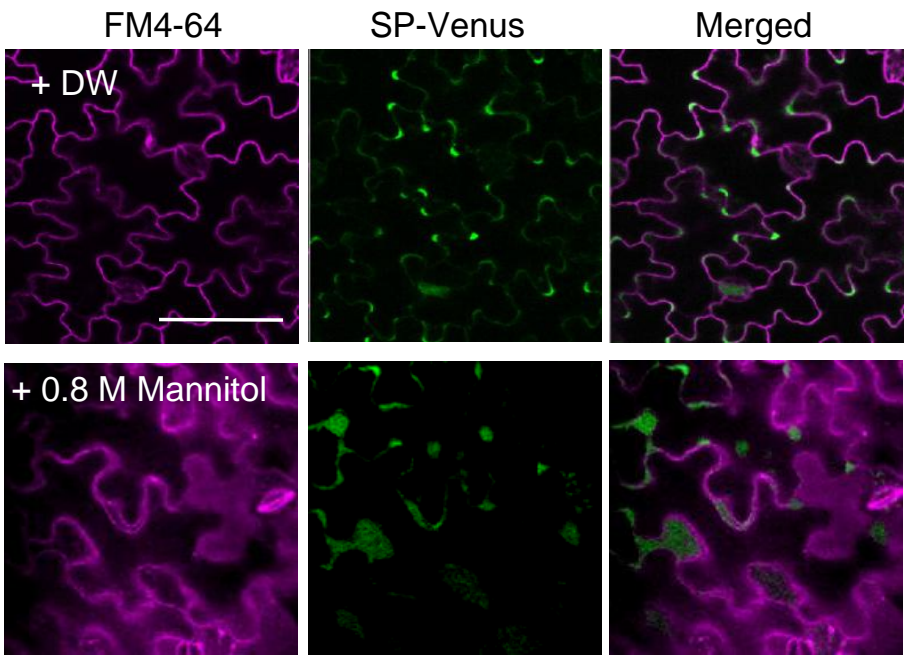

b
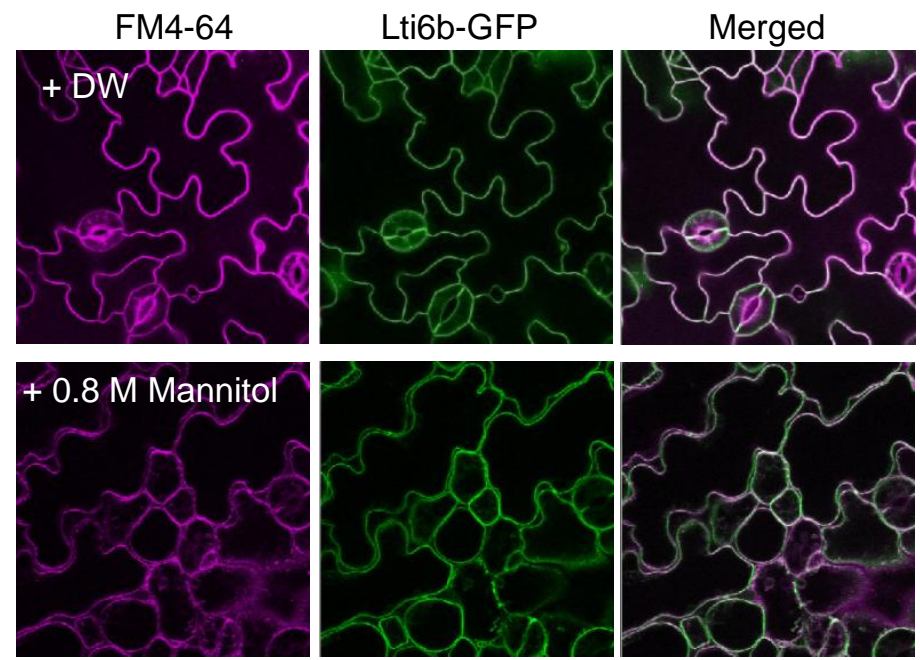

Supplementary Figure 4. Control experiment of Figure $2 \mathrm{e}$ showing secretion of stomagen outside the cells.

Confocal images of abaxial sides of 3-DAG cotyledons of transgenic plants that overexpressed a secreted form of GFP (SP-Venus, a) or a plasma membrane marker (Lti6b-GFP, b). Both untreated cells $(+D W)$ and plasmolyzed cells in $0.8 \mathrm{M}$ mannitol (+Mannitol) were inspected. Plasma membrane was counterstained with FM4-64. Bars, $50 \mu \mathrm{m}$. 


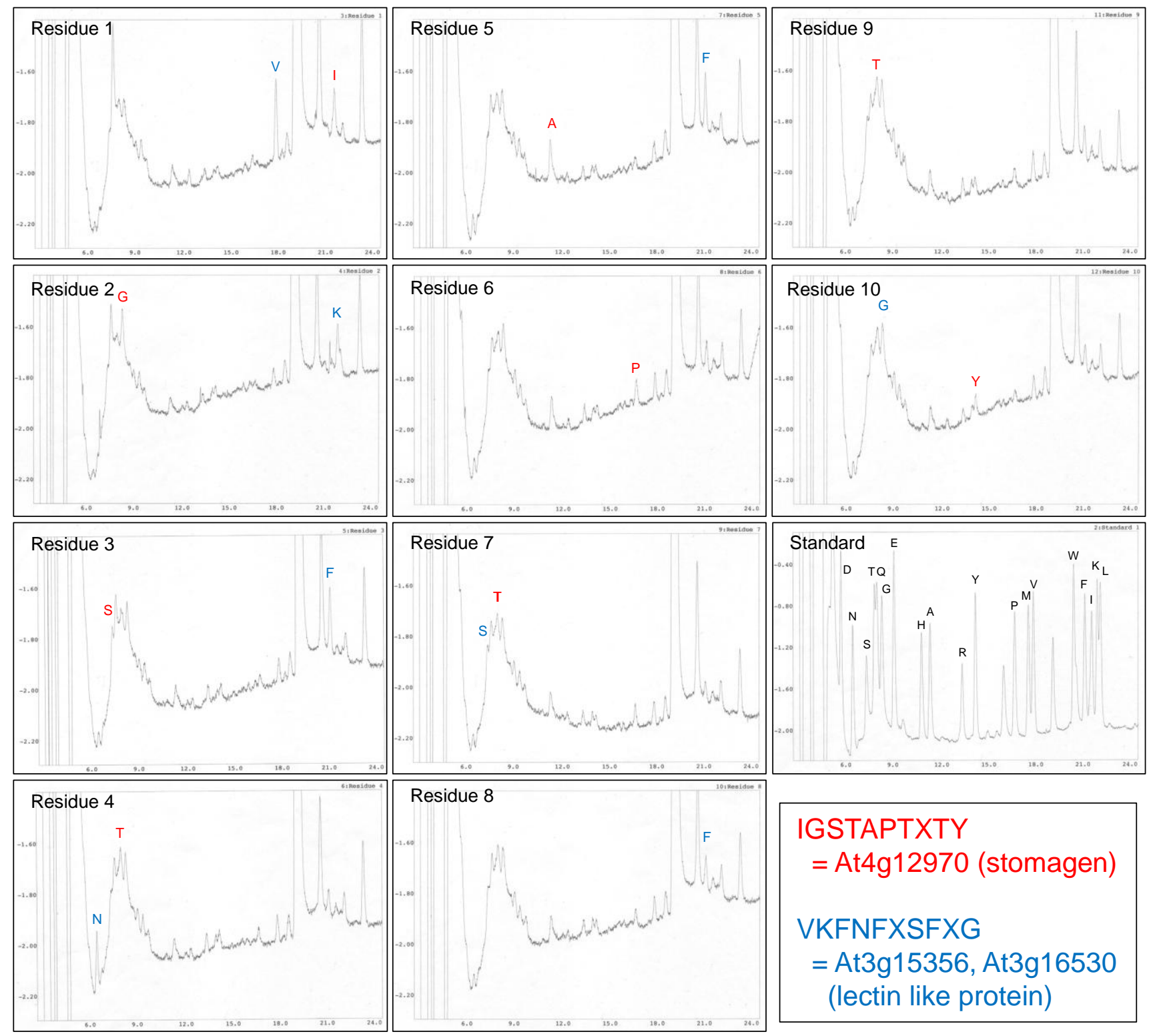

Supplementary Figure 5. Determination of the N-terminus of stomagen.

STOMAGEN-Venus that was expressed in Arabidopsis was pulled down with anti-GFP beads. The pulled down protein was subjected to automatic peptide sequencer to determine the $\mathrm{N}$-terminal sequence. Each panel shows the chromatogram of each cycle of the Edman degradation. The $\mathrm{N}$-terminal sequence of stomagen was determined to be IGSTAPTXTY (X is not determined). Another sequence (VKFNFXSFXG) detected in this analysis was derived from contaminated lectin-like protein of Arabidopsis (At3g15356 or At3g16530). 
Arabidopsis thaliana

Olyza sativa

Vitis vinifera

Populus trichocarpa

Selaginella moellendorffii

Arabidopsis thaliana

Olyza sativa

Vitisvinifera

Populus trichocarpa

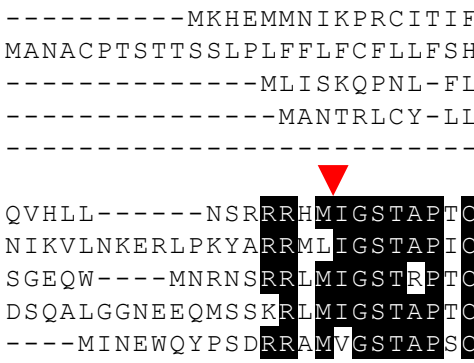

CHR-

CHR -

CHR- -

CHR- -

CRKRH
Selaginella moellendorffii

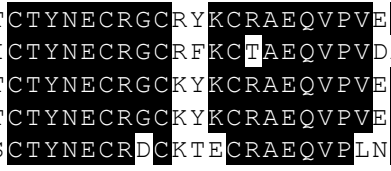

GNDPINSAYHY AND PMNSAYHY GN D P INSAYHY

RCV 10

DIMIKI 104

Arabidopsis thaliana

Olyza sativa

Populus trichocarpa

Selaginella moellendorffii
CTYNECRD

\section{Supplementary Figure 6. Stomagen orthologous proteins in vascular plants.} Multiple alignment of stomagen orthologous proteins conducted by Clustal W. Stomagen-like proteins are found in various plants, including Oryza sativa (Os01g0914400), Vitis vinifera (AM444732), and Populus trichocarpa (Pt02g2557). A similar sequence was also found in Selaginella moellendorffii (Sm084711), a primitive vascular plant. Conserved amino acids among these species are shown in reverse. The N-terminus of stomagen in Arabidopsis is shown by a red arrowhead. 

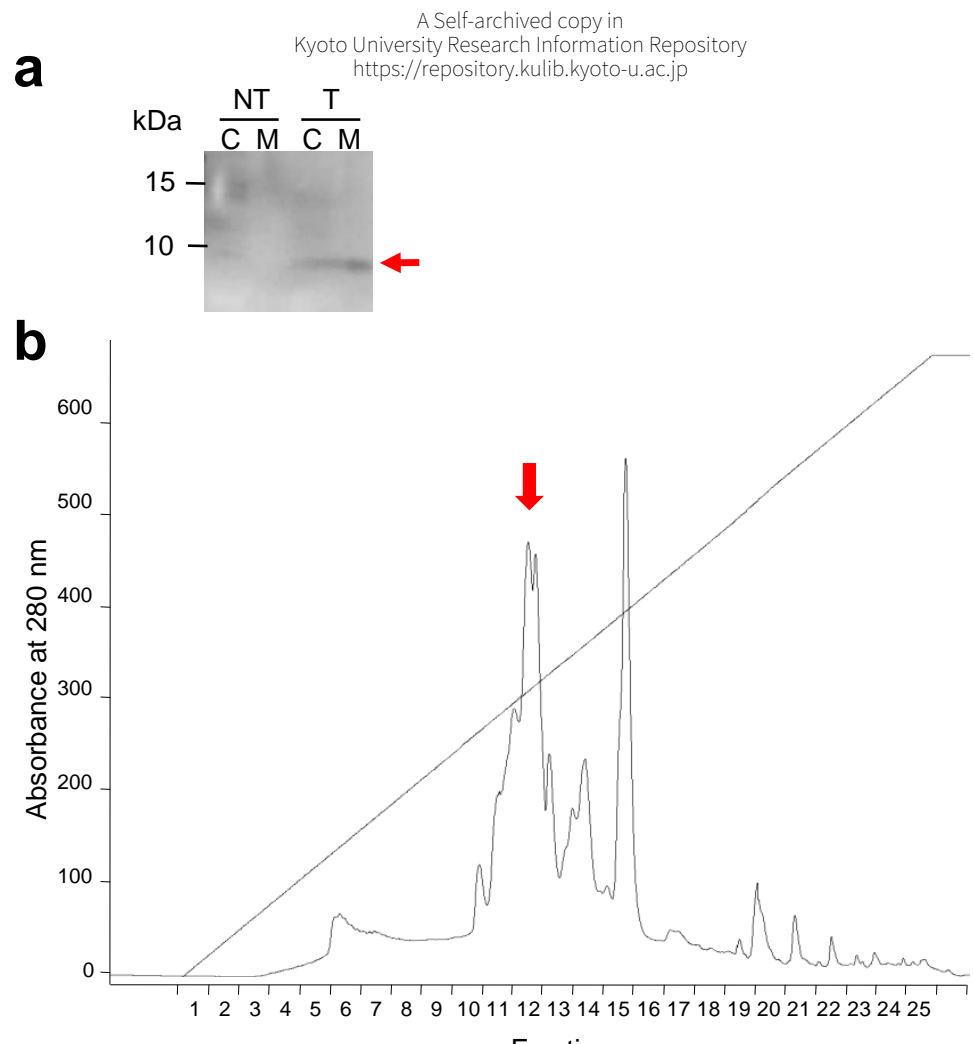

C

Fraction

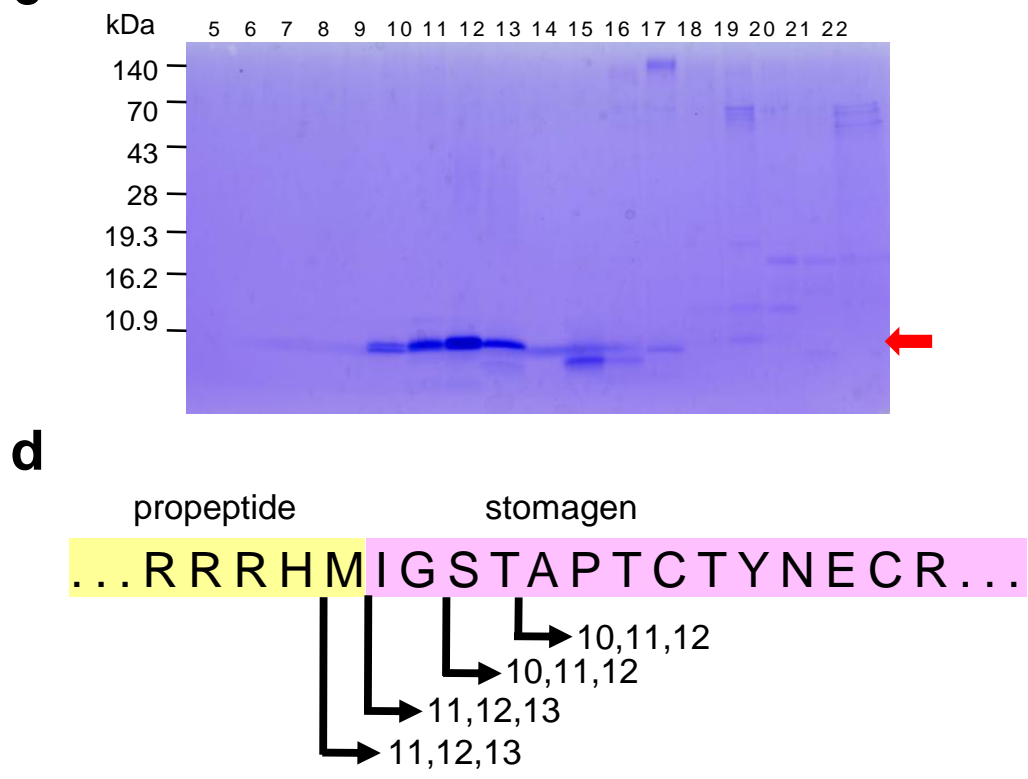

Supplementary Figure 7. Purification of the recombinant stomagen that was expressed in tobacco-cultured BY-2 cells.

a, An immunoblot with anti-stomagen antibody showing that stomagen was detected in the culture medium (M) but not in transformed cells (C). T indicates transformed BY-2 cells and NT indicates non-transformed BY-2 cells.

b, A chromatogram of purification of recombinant stomagen using a reverse-phase C-18 column.

A red arrow indicates the elution position of the recombinant stomagen.

c, SDS-PAGE with CBB staining of each eluted fraction of the chromatography. The stomagen was recovered in fraction numbers from 10 to 13. A red arrow indicates the position of purified recombinant stomagen in the chromatography in $\mathbf{b}$.

d, $\mathrm{N}$-terminal sequences of the recombinant stomagen in each fraction from 10 to 13 as determined by Edman degradation. 

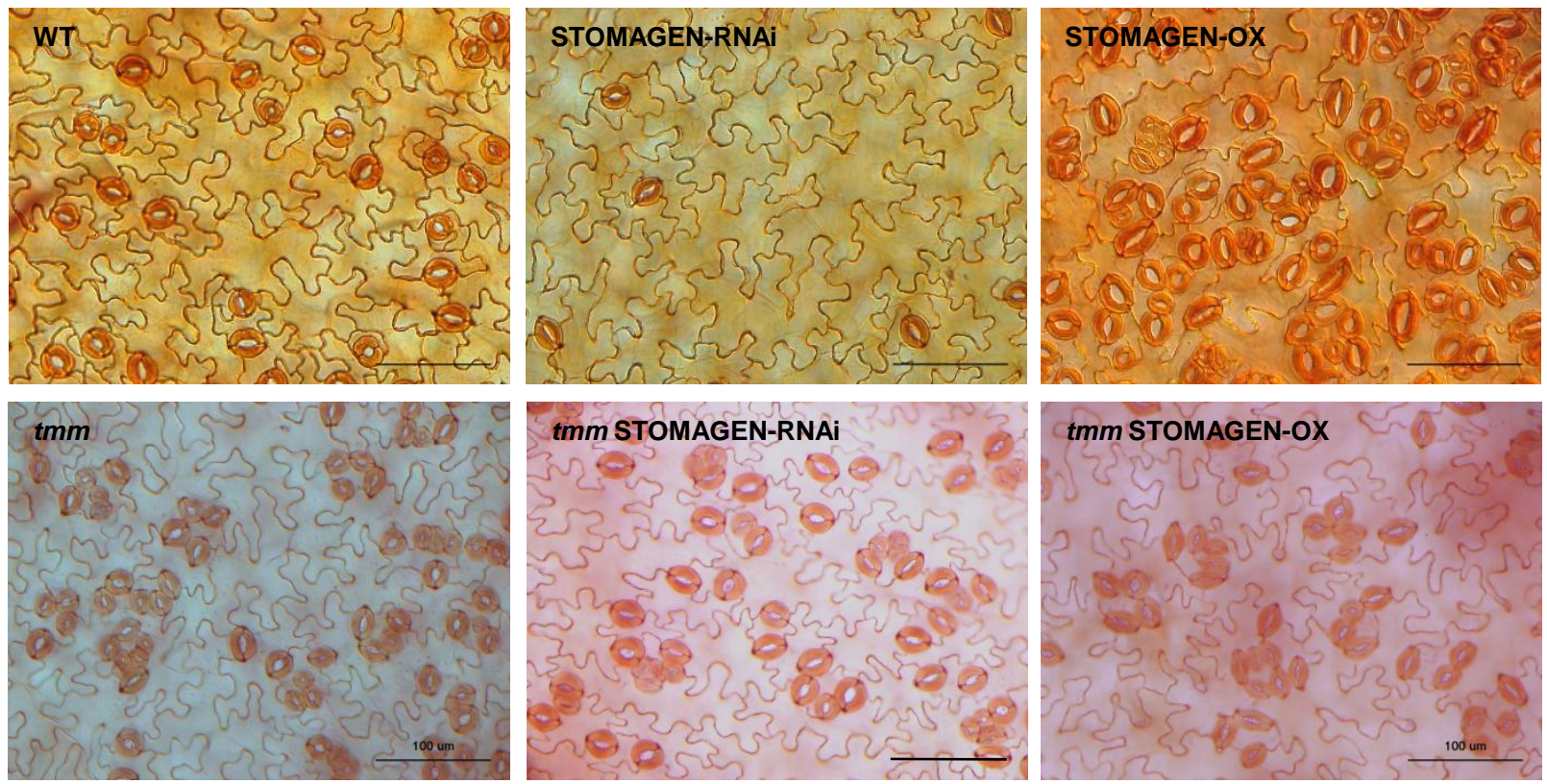

b
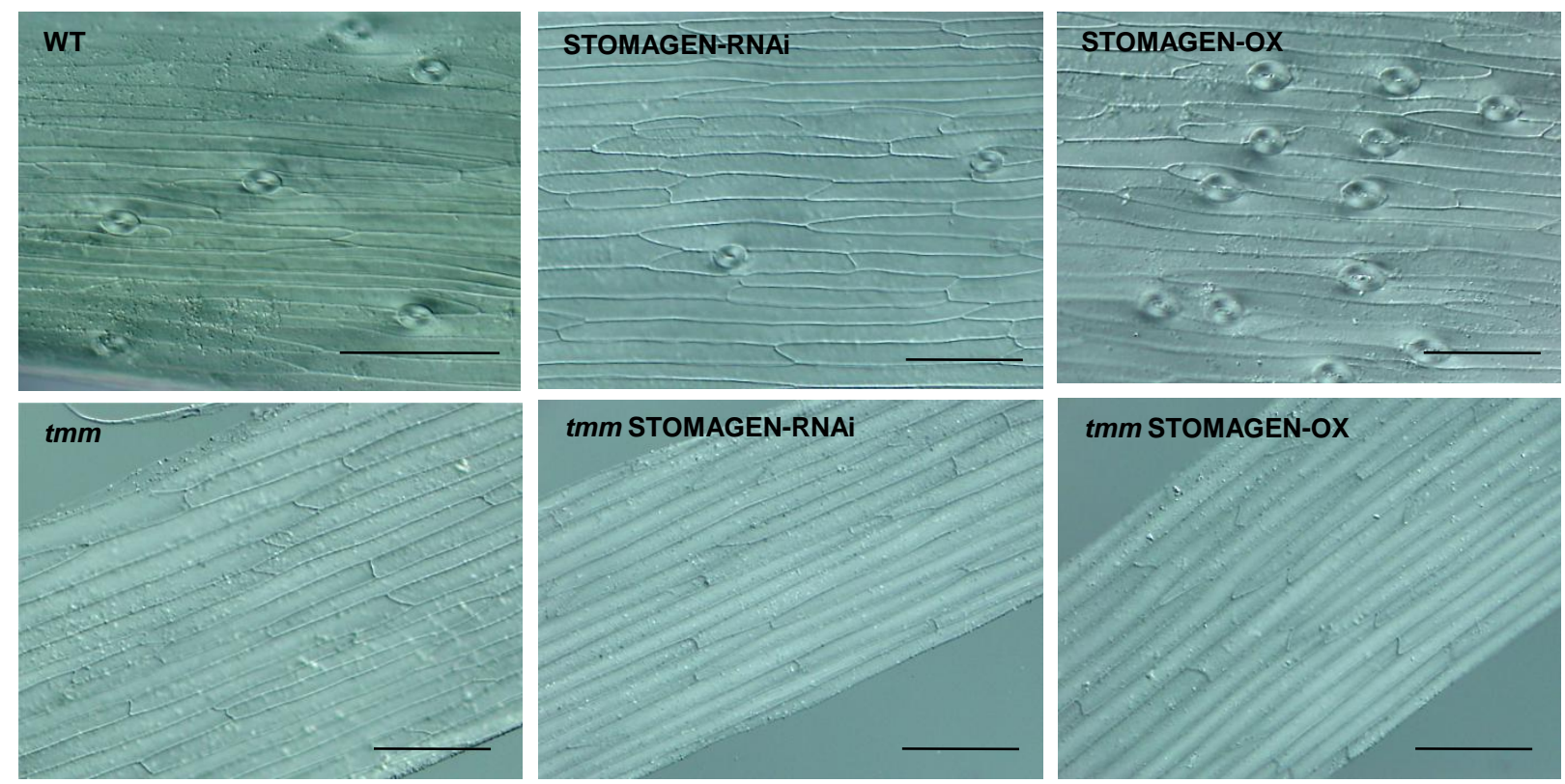

tmm STOMAGEN-OX

Supplementary Figure 8. Representative images of STOMAGEN-OX or STOMAGENRNAi in tmm background.

a, DIC images of the abaxial epidermis of mature first leaf of the wild type (WT), STOMAGEN-RNAi10, STOMAGEN-OX10, tmm, tmm STOMAGEN-RNAi8, tmm STOMAGEN-OX8. Quantitative data of stomatal density in each line are presented in Fig. 4b. Bars, $100 \mu \mathrm{m}$.

b, DIC images of the stems of the wild type (WT), STOMAGEN-RNAi10, STOMAGENOX10, tmm, tmm STOMAGEN-RNAi8, tmm STOMAGEN-OX8. Quantitative data of stomatal density in each line are presented in Fig. 4b. Bars, $100 \mu \mathrm{m}$. 

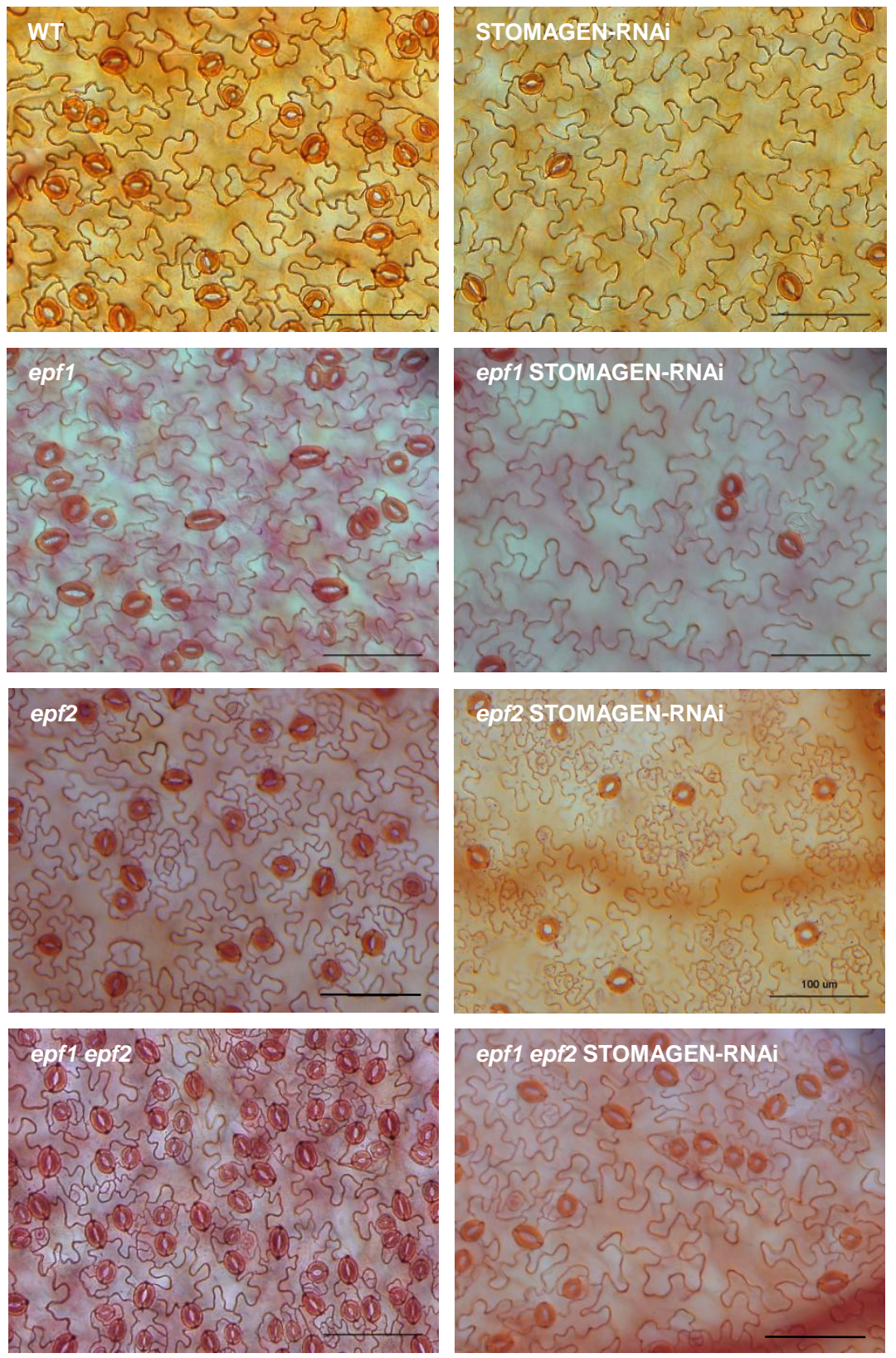

Supplementary Figure 9. Representative images of STOMAGEN-RNAi in epf backgrounds.

DIC images of the abaxial epidermis of mature first leaf of each of the wild type (WT), STOMAGEN-RNAi10, epf1, epf1 STOMAGEN-RNAi8, epf2, epf2 STOMAGEN-RNAi8, epf1 epf2, and epf1 epf2 STOMAGEN-RNAi8. Quantitative data of stomatal density in these lines are presented in Fig. 4 (c, d). Bars, $100 \mu \mathrm{m}$. 


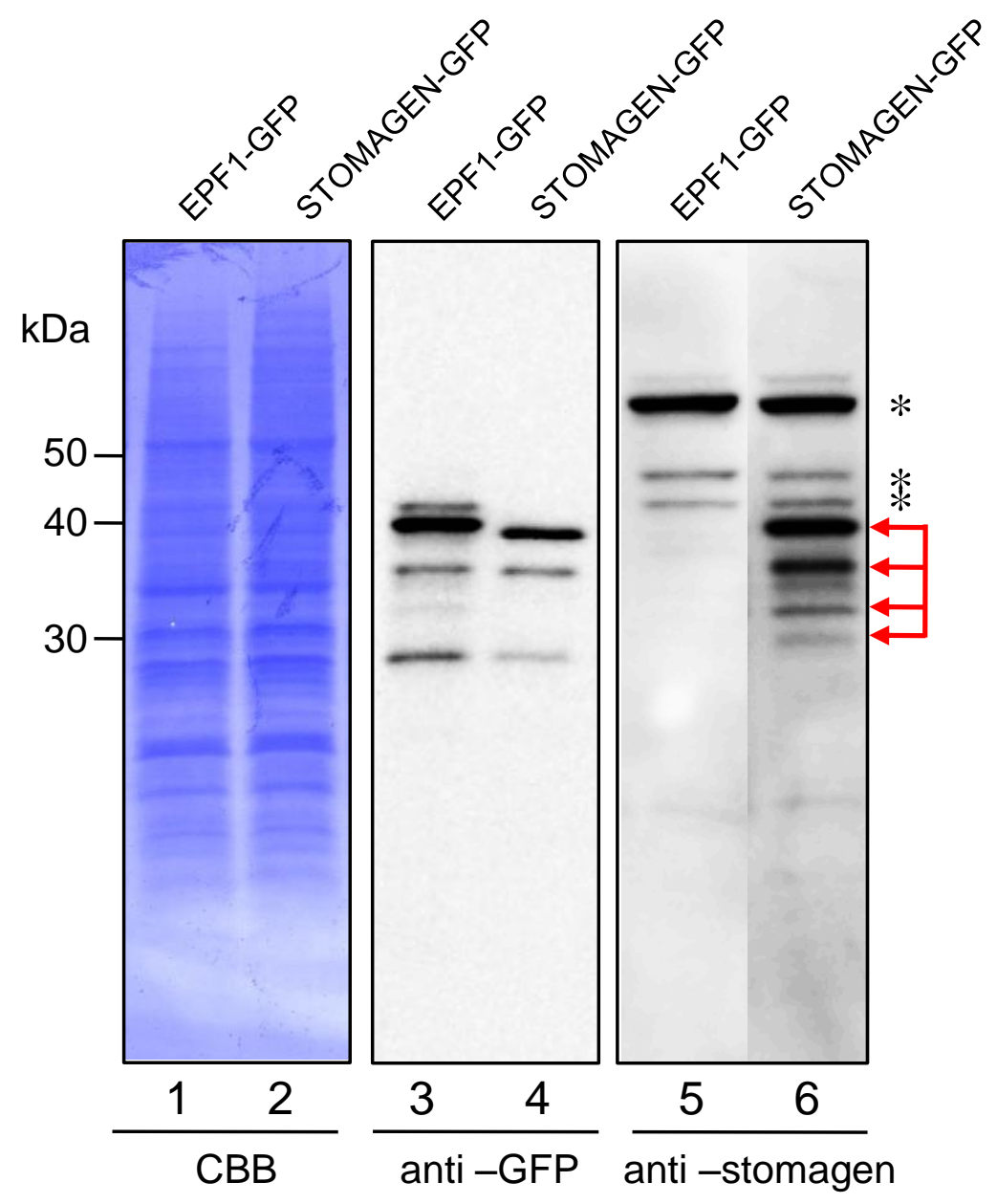

Supplementary Figure 10. Specificity of anti-stomagen antibody used in this study. Both EPF1-GFP (lanes 1, 3 and 5) and STOMAGEN-GFP (lanes 2, 4 and 6) were expressed in tobacco-cultured BY-2 cells. Whole homogenate of the BY-2 cells were subjected to SDS-PAGE followed by either Coomassie blue (CBB) staining or by immunoblot with anti-GFP antibody or anti-stomagen antibody. Red arrows indicate the specific bands of STOMAGEN-GFP. Asterisks indicate non-specific signals. 


\section{Supplementary Table 1. Co-expressed genes with TMM, SDD1, and EPF1.} STOMAGEN gene is colored in red. Known genes regulating stomatal development are colored in blue. This table was made using ATTED-II (http://atted.jp/). Details are in Full Method.

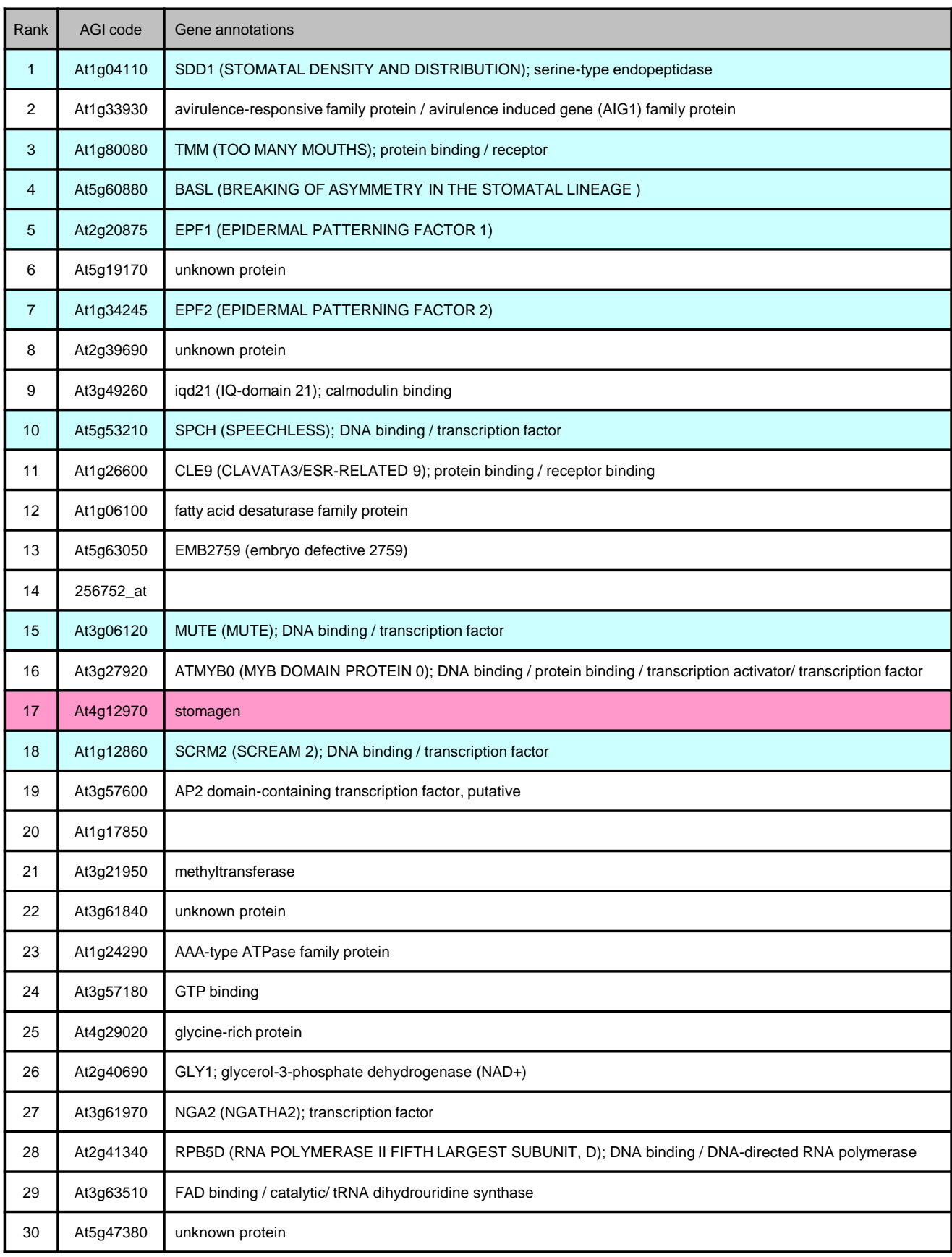


Supplementary Table 2 Primers used in this study

\begin{tabular}{|c|c|c|}
\hline Purpose & Name & Sequence $\left(5^{\prime}->3^{\prime}\right)$ \\
\hline \multirow[t]{2}{*}{ STOMAGEN promoter cloning } & P10_prom_F & CACCTAGAAAAGATTTGCTTCCTAAAC \\
\hline & P10_prom_R & TCTCTACTTCTTCTTCTTCTTGCTC \\
\hline \multirow[t]{2}{*}{ STOMAGEN coding region cloning } & P10_F & CACCGAATGAAGCATGAAATGATGAACATC \\
\hline & P10_R & ACAACTATTATCTATGACAAACACATCTA \\
\hline \multirow[t]{2}{*}{ EPF1 coding region cloning } & EPF1_F & CACCATGAAGTCTC TTCTTCTCCT TGCCTT \\
\hline & EPF1_R & TCAAGGGACAGGGTAGGACTTATTGTT \\
\hline \multirow[t]{2}{*}{ GFP amplification } & GFP-CfusF Bst & $\begin{array}{l}\text { ATAGGTCACCTGGTGGTGGTGGTATTGAAGGTAGAAGTAAAGGAGAA } \\
\text { GAACTTTTC }\end{array}$ \\
\hline & GFP-CfusR Bst & $\begin{array}{l}\text { TATGGTTACCTTAATGGTGATGGTGATGGTGATGGTGTTTGTATAGT } \\
\text { TCATCCATGC }\end{array}$ \\
\hline \multirow[t]{3}{*}{ Venus-g4 tag fusion to $\mathrm{C}$ terminal of STOMAGEN } & $\mathrm{P}-\mathrm{V} \_\mathrm{F}$ & TGTGTTTGTCATAGAATGGTGAGCAAGGGC \\
\hline & P-V_R & GCCCTTGCTCACCATTCTATGACAAACACA \\
\hline & Venus_R & TTACCCCCCССССССTTGTACAGC \\
\hline Secretory Venus-g4 & $2 \mathrm{Ssp} F$ & CACCatggccagactcacaagcatcattgccctct \\
\hline Reconbinant STOMAGEN production by E.coli. & P10m_F & caccCATATGATAGGGTCGACAGCACCAAC \\
\hline STOMAGEN silencing by artificial microRNA & CACC_amiA & CACCCTGCAAGGCGATTAAGTTGGGTAAC \\
\hline \multirow[t]{4}{*}{ For amiA } & P10ami1_I miR-s & gaTACATCTATAATGATAAGCGCtctctcttttgtattcc \\
\hline & P10ami1_II miR-a & gaGCGCTTATCATTATAGATGTAtcaaagagaatcaatga \\
\hline & P10ami1_III miR*s & gaGCACTTATCATTAAAGATGTTtcacaggtcgtgatatg \\
\hline & P10ami1_IV miR*a & gaAACATCTTTAATGATAAGTGCtctacatatatattcct \\
\hline \multirow[t]{5}{*}{ ForamiB } & P10ami2_ImiR-s & gaTACATCTATAATGATAAGCGCtctctcttttgtattcc \\
\hline & P10ami2_IImiR-a & gaGCGCTTATCATTATAGATGTAtcaaagagaatcaatga \\
\hline & P10ami2_IIImiR*s & gaGCACTTATCATTAAAGATGTTtcacaggtcgtgatatg \\
\hline & P10ami2_IVmiR*a & gaAACATCTTTAATGATAAGTGCtctacatatatattcct \\
\hline & amiB & GCGGATAACAATTTCACACAGGAAACAG \\
\hline \multirow[t]{2}{*}{ STOMAGEN silencing by dsRNA } & P10_RNAi_F & CACCGATAGGGTCGACAGCACCAA \\
\hline & P10_RNAi_R & TCATATCTATGACAAACACATCTATAA \\
\hline \multirow[t]{8}{*}{ Genotyping primer } & tmm SALK_011958-LP & ATGGCACGATATGAATTCTTCCGCCAA \\
\hline & SALK_011958-RP & ACTAGATATTAGCATAAAAATGAAATTAGG \\
\hline & epf1SALK_137549-LP & TTTTTCATTATTCGCTTAAAGTGTAG \\
\hline & SALK_137549-RP & AGCAAAAGGAAAACAAAACGG \\
\hline & epf2SALK_047918-LP & TAAAACCTCTGCCTCAACCAG \\
\hline & SALK_047918-RP & TTACCGGTATGATGGAGATGG \\
\hline & spch SAIL_36_B6 LP & GAAAAACCTAGATCCTCCCCC \\
\hline & SAIL_36_B6_RP & TCCTATGATCGATGCTTGGTC \\
\hline
\end{tabular}

